\title{
ESTRUTURA E FLORÍSTICA DE UMA FLORESTA DE RESTINGA EM IPITANGAS, Saquarema, Rio de Janeiro, BrasiL ${ }^{1}$
}

\author{
Cyl Farney Catarino de Sán \& Dorothy Sue Dunn de Araujo ${ }^{3}$
}

\begin{abstract}
ReSUMO
(Estrutura e florística de uma floresta de restinga em Ipitangas, Saquarema, Rio de Janeiro, Brasil) A restinga de Ipitangas abriga um dos últimos remanescentes de floresta de restinga livre de inundação entre Marambaia e Cabo Frio. A estrutura desta floresta foi estudada utilizando o método de ponto quadrante central utilizandose dois critérios: DAP $\geq 5$ e DAS $\geq 5$. Foram encontradas 108 espécies distribuídas em 34 famílias, sendo Myrtaceae, Leguminosae e Sapotaceae as mais ricas. As espécies Algernonia obovata, Pterocarpus rohrii, Pseudopiptadenia contorta, Guapira opposita, Alseis involuta, Simaba cuneata, Astronium graveolens, Eriotheca pentaphylla e Ocotea complicata prevalecem entre as dez de maior valor de importância tanto na análise a partir do DAP como do DAS. Pouteria grandiflora destaca-se como uma espécie com elevada proporção de indivíduos com troncos múltiplos, tanto em relação ao DAP quanto ao DAS, enquanto Algernonia obovata e Pterocarpus rohrii apresentam destacadas proporções quando se consideram as medidas de DAS. As dominâncias totais obtidas a partir do DAP $\left(23,3 \mathrm{~m}^{2} / \mathrm{ha}\right)$ e do DAS $\left(39,2 \mathrm{~m}^{2} / \mathrm{ha}\right)$ são influenciadas principalmente pela forma dos troncos e das raízes tabulares de algumas espécies e pelos troncos múltiplos. A floresta de restinga em Ipitangas apresentou maior similaridade florística com áreas do Centro de Diversidade Vegetal de Cabo Frio e do Espírito Santo do que com as restingas de São Paulo e do litoral sul do Brasil.
\end{abstract}

Palavras-chave: fitossociologia, floresta atlântica, troncos múltiplos, centro de diversidade, Cabo Frio, Jacarepiá.

Abstract

(Structure and flora of a restinga forest at Ipitangas, Saquarema, Rio de Janeiro, Brazil) The Ipitangas Restinga is home to one of the last remnants of non-flooded restinga forest on the coast of Rio de Janeiro state, from Marambaia to Cabo Frio. Forest structure was studied using the point-centered quadrant method and minimum diameter of $5 \mathrm{~cm}$ at breast height and at soil level. A total of 108 species were recorded in 34 families; Myrtaceae, Leguminosae and Sapotaceae were the most species-rich families. Algernonia obovata, Pterocarpus rohrii, Pseudopiptadenia contorta, Guapira opposita, Alseis involuta, Simaba cuneata, Astronium graveolens, Eriotheca pentaphylla and Ocotea complicata were among the ten most important species based on Importance Value (IV) calculated from both breast height and soil level diameters. Pouteria grandiflora had the highest number of multiple trunks based on both diameter measurements, while Algernonia obovata and Pterocarpus rohrii had high numbers of multiple trunks when taken into consideration soil level diameter. Total dominance based on breast height diameter was $23.2 \mathrm{~m}^{2} /$ ha while that using soil level diameter was $39.2 \mathrm{~m}^{2} / \mathrm{ha}$. These results are influenced mainly by trunk shape, the presence of buttresses and by multiple trunks. The forest at Ipitangas had greater floristic similarity when compared to areas in the Cabo Frio Center of Plant Diversity and in the state of Espírito Santo than when compared to areas on the coast south of Rio de Janeiro state.

Key words: phytosociology, Atlantic forest, multiple trunks, Center of Plant Diversity, Cabo Frio, Jacarepiá forest.

\section{INTRODUÇÃo}

Nos últimos 20 anos, as diversas comunidades vegetais das planícies arenosas da costa brasileira e dos campos de dunas, conhecidas como vegetação de restinga vêm sendo estudadas mais intensamente e documentadas com coleções científicas - um dos pilares dos estudos de comunidades e populações. Essas comunidades, incluídas no bioma Mata Atlântica, são consideradas um habitat marginal ou periférico (Scarano 2002) onde as condições estressantes para o estabelecimento e desenvolvimento das plantas (e.g., salinidade, ventos fortes, profundidade do lençol freático

Artigo recebido em 05/2008. Aceito para publicação em 02/2009.

${ }^{1}$ Trabalho realizado dentro das Linhas de Ação em Botânica do CNPq; fase final apoiada pela Fundação O Boticário de Proteção à Natureza e a Fundação MacArthur.

${ }^{2}$ Instituto de Pesquisas Jardim Botânico do Rio de Janeiro, R. Pacheco Leão 915, 22460-030, Rio de Janeiro, RJ, Brasil ${ }^{3}$ Universidade Federal do Rio de Janeiro, Instituto de Biologia/Depto. de Ecologia, Rio de Janeiro, RJ. 
e fertilidade dos solos) selecionam espécies que espelham composições florísticas distintas para cada comunidade.

A vegetação das planícies arenosas costeiras está sendo rapidamente destruída ao longo de quase toda a costa brasileira, sem o conhecimento de sua riqueza florística, estrutura e potencialidades. Dentre as diversas comunidades vegetais desta estreita faixa, destaca-se as formações arbóreas que incluem as florestas inundadas (periódica e permanentemente) e livres de inundação (Lacerda et al. 1993). Essas comunidades arbóreas são mais conhecidas no litoral sul (e.g., Silva et al. 1994; Dornelles \& Waechter 2004; Scherer et al. 2005) e sudeste (e.g., Sá 1996, 2002; Sugiyama 1998; Lobão \& Kurtz 2000; Assumpção \& Nascimento 2000; Assis et al. 2004) do que no nordeste (Trindade 1991; Zickel et al. 2004) e norte (Bastos 1996), retratando parcialmente a complexidade dessa formação ao longo do litoral onde a presença de espécies arbóreas e arbustivas com troncos múltiplos tem sido apontadas como resposta a distúrbios (Sá 1996, 2002; Carvalhaes \& Mantovani 1998; Assumpção \& Nascimento 2000). Entretanto a verifição de troncos múltiplos como atributo natural de espécies na estrutura dessas florestas requer que as mensurações sejam realizadas também a partir do nível do solo, como no estudo realizado por Dunphy et al. (2000) em Porto Rico.

No estado do Rio de Janeiro, dos cerca de 105.000 ha de restingas remanescentes, 43.579 ha apresentam-se comprometidos por diversas fontes de degradação (Rocha et al. 2007). Os principais remanescentes florestais estão situados esparsamente nas planícies arenosas dos municípios de Angra dos Reis (Ilha Grande), Rio de Janeiro (Marambaia), Saquarema (Ipitangas), Araruama e Arraial do Cabo (Massambaba), Cabo Frio (Campos Novos), Macaé, Carapebus e Quissamã (Jurubatiba), e nas complexas planícies formadas sob influência do Rio Paraíba do Sul em Campos, São João da Barra e São Francisco do Itabapoana. Em apenas três dessas áreas, extensões de florestas de tamanhos variados estão protegidas dentro dos limites de Unidades de Conservação: Reserva Biológica Estadual da Praia do Sul (Ilha Grande), Parque Nacional da Restinga de Jurubatiba e Área de Proteção Ambiental de Massambaba, na localidade conhecida como Ipitangas próxima a Lagoa de Jacarepiá, no município de Saquarema, uma das mais bem preservadas. Esta última está inserida no Centro de Diversidade Vegetal de Cabo Frio (Araujo 1997).

O manejo efetivo de unidades de conservação depende de conhecimentos sobre os ecossistemas ali contidos, e neste contexto diversos estudos sobre vegetação e flora foram conduzidos na Restinga de Ipitangas (Freitas 1990/1992; Sá 1992, 1996, 2002; Sarahyba 1993; Cirne \& Scarano 1996, 2001; Almeida \& Araujo 1997; Lopez et al. 1998; Barros 2009, neste volume; Fontoura et al. 2009, neste volume; Araujo et al. 2009, neste volume), realizados principalmente através de um acordo de cooperação técnica firmado entre o Instituto de Pesquisas Jardim Botânico do Rio de Janeiro e a FEEMA (Projeto Restinga) que vigorou entre 1992 e 1995. Desta forma o presente estudo tem por objetivo descrever as principais características estruturais e florísticas de um trecho da floresta de restinga em Ipitangas, utilizando o método de ponto-quadrantes e comparar os resultados com aqueles de outros estudos realizados em formações semelhantes no litoral sul e sudeste do Brasil.

\section{Materiale Métodos \\ Área de Estudo}

A Área de Proteção Ambiental de Massambaba foi criada pelo Decreto Estadual № 9529-C de 15/12/1986 com área de 76,3 km², e é administrada pela Fundação Estadual de Engenharia do Meio Ambiente. Este mesmo decreto (Dec. Est. 9529-A e B) designou duas áreas, uma na extremidade ocidental e outra na oriental desta unidade de conservação como áreas declaradas "de utilidade pública para fins de desapropriação", que seriam respectivamente as Reservas Ecológicas Estaduais de Jacarepiá 
e Massambaba. Entretanto, estas reservas nunca foram efetivamente criadas, apesar da primeira constar como tal em diversas publicações científicas (e.g., Almeida \& Araujo 1997; Sá 1992, 1996, 2002).

O clima da área litorânea compreendida entre Niterói e Cabo Frio é em sua maior parte do tipo Aw - Tropical com Chuvas de Verão e Secas de Inverno de acordo com o sistema de Köppen (Barbiére 1981). Os ventos predominantes na região são os do quadrante nordeste (com percentuais superiores a $40 \%$ em qualquer estação do ano, frequiência superior a $51 \%$ no verão e no inverno, e velocidade média maior no inverno (5,1 a $6,4 \mathrm{~m} / \mathrm{segundo}$ ). Esses ventos são quentes e secos e influenciam o comportamento das demais variáveis climáticas, sobretudo evaporação e pluviosidade (Barbiére 1997). A temperatura média anual em Cabo Frio situa-se entre $25^{\circ} \mathrm{C}$ no verão e $20^{\circ} \mathrm{C}$ no inverno, com médias das máximas de $28^{\circ} \mathrm{C}$ no verão e das mínimas de $24,3^{\circ} \mathrm{C}$ no inverno (Barbiére 1997). A precipitação média anual para grande parte da região do Centro de Diversidade Vegetal de Cabo Frio (Araujo 1997) é menor que 1000 mm (Barbiére \& Coe Neto 1999), sendo registrados em Saquarema 934,4 mm. A umidade relativa do ar em Cabo Frio é alta, tendo ficado entre $81 \%$ e $85 \%$ ao longo de seis decênios de análise (Barbiére 1997).

Os solos da área de estudo são compostos pelos seguintes tipos, de acordo com o levantamento realizado por Carvalho et al. (2000): Neossolos fúlvicos - em áreas aluvionares relacionadas aos tributários da Lagoa de Saquarema; Neossolos Quartzarênicos - em áreas de restinga com vegetação herbácea; Espodossolos - principalmente em áreas de restinga com vegetação arbustiva e arbórea; e Argissolos em áreas de relevos ondulados e montanos. Os solos arenosos são de baixa fertilidade como é comum em áreas de restinga.

A vegetação nativa remanescente encontra-se nos dois cordões arenosos, na área intercordões, nas margens da Lagoa de Jacarepiá (ver Barros 2009) e na ilha de Jacarepiá onde há um pequeno reamanescente de floresta sobre solo argiloso. Os demais morros dos arredores da lagoa já tiveram sua vegetação totalmente alterada. A floresta de restinga situada no cordão arenoso interno já ocupou uma área mais extensa (antes de 1980 parte da área já havia sido alterada) e posteriormente, em 1986, o loteamento Vilatur Saquarema iniciou o desmatamento, que aos poucos vai se regenerando naturalmente (Sá 2002). A faixa de floresta onde foi realizado o presente estudo (225'39'S; 42 $26^{\prime} 50^{\prime \prime} \mathrm{W}$ ) já sofreu alguns cortes seletivos para retirada de árvores de valor econômico, cujas evidências são troncos rebrotados com cicatrizes de cortes. Com a criação da Área de Proteção Ambiental de Massambaba e, posteriormente, das Zonas de Preservação da Vida Silvestre, junto ao Plano de Manejo da APA, as atividades antrópicas diminuíram mas não cessaram.

A floresta onde foi realizado este estudo (aqui chamada de "floresta de Jacarepiá") está localizada no cordão arenoso interno da restinga de Ipitangas, que está situada sob sedimentos de idade pleistocênica. (Turcq et al. 1999). Os solos são bem drenados onde o lençol freático está a mais de $7 \mathrm{~m}$ de profundidade (Sá \& Araujo, dados não publicados). A diferença de altura entre o cordão externo e o cordão interno é em torno de 2 a $4 \mathrm{~m}$, um padrão típico do litoral sudeste (Muehe \& Valentini 1998).

\section{Amostragem}

O método utilizado para obter os parâmetros fitossociológicos foi o pontoquadrante central, baseado em Martins (1991) com pequenas modificações, que já está amplamente difundido e utilizado em estudos de vegetação arbórea no Brasil. Este método foi aplicado em 200 pontos localizados ao longo de 20 linhas (espaçamento das linhas: $20 \mathrm{~m}$; dos pontos: $10 \mathrm{~m}$ ). Estas linhas secundárias basearam-se em duas linhas base de $200 \mathrm{~m}$ de comprimento, traçadas perpendicularmente ao comprimento do cordão interno de restinga e distanciadas aproximadamente $150 \mathrm{~m}$ entre si. A distância de $10 \mathrm{~m}$ entre os pontos foi estabelecida com base em 100 medições de 
distâncias entre árvores na área de estudo, conforme recomenda Martins (1991).

Os quadrantes ao redor de cada ponto de amostragem foram estabelecidos por uma cruzeta de madeira deitada perpendicularmente a linha, e foram sempre numerados no sentido anti-horário. Foram considerados como ocorrentes em um quadrante indivíduos cujas bases encontravam-se totalmente dentro deste. Indivíduos com bases divididas pela linha que separava dois quadrantes foram considerados como ocorrendo no quadrante à esquerda da linha.

Foram tomadas as medidas de distância ponto-individuo, diâmetro a altura do peito (DAP $\geq 5 \mathrm{~cm}$ ), diâmetro a altura do solo (DAS $\geq 5 \mathrm{~cm}$ ) e altura máxima (estimada utilizando um podão de vara de $10 \mathrm{~m}$ como referência). O material botânico referente a cada indivíduo foi coletado mesmo em estado estéril. Foram considerados somente os indivíduos vivos. Cada árvore amostrada recebeu uma etiqueta plástica rotulada com números referentes a sua localização, e fixadas com pregos de cobre. No caso de indivíduos com mais de um tronco saindo do solo a partir de um único ponto, incluímos somente aqueles troncos que possuíssem os diâmetros mínimos estabelecidos. O trabalho de campo foi realizado no período compreendido entre 1990 e 1993. O material botânico foi identificado utilizando chaves de famílias, gêneros e espécies, comparação com exsicatas já determinadas no herbário do Instituto de Pesquisas Jardim Botânico do Rio de Janeiro, e consulta a especialistas. Foi adotado o sistema de classificação de Cronquist (1988), exceto para a família Leguminosae, que seguiu Polhill et al. (1981). O material testemunho está depositado no herbário do Instituto de Pesquisas Jardim Botânico do Rio de Janeiro (RB).

Os parâmetros fitossociológicos de densidade, dominância, frequência absoluta e relativas, valor de importância (VI), valor de cobertura (VC) e ainda o índice de diversidade de Shannon (H') e a equabilidade (J) foram calculados através do Programa FITOPAC 1.6 (Shepherd 2006). A similaridade entre a área estudada e outras áreas do litoral sul e sudeste foi calculada par a par utilizando o índice de Jaccard (Magurran 1988). A riqueza de espécies (S) foi considerada como sendo o número total de espécies no levantamento e corresponde a diversidade alfa de Whittaker (1972).

\section{Resultados}

No inventário realizado na floresta de restinga de Ipitangas foram amostrados 800 indivíduos arbóreos e arbustivos, distribuídos em 108 espécies (três morfoespécies), 77 gêneros e 34 famílias (Tab. 1). As três morfoespécies, não identificadas até família, não estão representadas na Tabela 1 . As cinco famílias mais ricas em espécies são Myrtaceae (21 spp.), Leguminosae (15 spp.), Sapotaceae (9 spp.), Euphorbiaceae (5 spp.) e Sapindaceae (5 spp.); concentrando 52,3\% da riqueza e um total de 51,7\% dos indivíduos da amostragem. Um total de 16 famílias foram representadas por apenas uma espécie (Tab. 2).

A amostragem realizada utilizando o DAP $\geq 5 \mathrm{~cm}$ como critério de inclusão apresentou uma densidade total de 1.597 indivíduos/ha e área basal total de $23,3 \mathrm{~m}^{2} / \mathrm{ha}$. A distância média entre os indivíduos foi de $2,5 \mathrm{~m}$. O índice de diversidade de Shannon ( $H^{\prime}$ ) foi de 4,06 e a equabilidade (J) foi 0,87 .

A altura média da mata foi $8 \pm 2,7 \mathrm{~m}$; e $49 \%$ dos indivíduos apresentaram alturas $\leq 7$ m (Fig. 1). No intervalo 3,1 a 7 m, 31 espécies apresentaram seus limites máximos em alturas (e.g., Inga maritima, Casearia oblongifolia, Capparis flexuosa, Gomidesia martiana). Entre 3 e $11 \mathrm{~m}$ de altura $63 \%$ das espécies apresentam seus limites, onde estão cerca de $88 \%$ dos indivíduos. Os três indivíduos emergentes atingiram entre $17 \mathrm{~m}$ (Eugenia copacabanensis e Pterocarpus rohrii) e $22 \mathrm{~m}$ (Neomitranthes langsdorfii).

$\mathrm{Na}$ distribuição diamétrica utilizando o DAP $\geq 5 \mathrm{~cm}$, um total de 50,2\% dos indivíduos amostrados concentraram-se entre as classes de 5 e $10 \mathrm{~cm}$ de DAP, sendo 39 espécies exclusivas a estes intervalos (Fig. 2). A concentração de indivíduos nas primeiras classes indica uma 
Tabela 1 - Lista das espécies encontradas no levantamento fitossociológico da floresta de restinga da Reserva Ecológica Estadual de Jacarepiá,Saquarema/RJ. Números entre parênteses nas famílias referem-se ao número de gêneros e espécies.

\begin{tabular}{|c|c|c|}
\hline Familia & Espécie & Coletor e $\mathbf{N}^{\circ}$ \\
\hline \multirow[t]{2}{*}{ ANACARDIACEAE $(2 / 2)$} & Astronium graveolens Jacq. & C.Farney 3194 \\
\hline & Spondias venulosa (Mart. ex Engl.) Engl. & C.Farney 3249 \\
\hline \multirow[t]{2}{*}{ ANNONACEAE (2/2) } & Duguetia sessilis (Vell.) Maas & C.Farney 3196 \\
\hline & Oxandra nitida R.E.Fries & C.Farney 3247 \\
\hline \multirow[t]{2}{*}{ APOCYNACEAE (2/2) } & Aspidosperma parvifolium A.DC. & C.Farney 3193 \\
\hline & Tabernaemontana laeta Mart. & C.Farney 3254 \\
\hline \multirow[t]{2}{*}{ BIGNONIACEAE (1/2) } & $\begin{array}{l}\text { Tabebuia aff. chrysotricha (Mart. } \\
\text { ex A.DC.) Standl. }\end{array}$ & C.Farney 3252 \\
\hline & Tabebuia sp. & C.Farney 3255 \\
\hline \multirow[t]{3}{*}{ BOMBACACEAE (3/3) } & Bombacopsis stenopetala (Casar.) A.Robyns & C.Farney 3189 \\
\hline & Eriotheca pentaphylla (Vell.) A.Robyns & C.Farney 3190 \\
\hline & $\begin{array}{l}\text { Pseudobombax grandiflorum } \\
\text { (Cav.) A.Robyns }\end{array}$ & C.Farney 3192 \\
\hline CACTACEAE (1/1) & Opuntia brasiliensis (Willd.) Haw. & C.Farney 3188 \\
\hline CAPPARACEAE $(1 / 1)$ & Capparis flexuosa (L.) L. & C.Farney 3235 \\
\hline CHRYSOBALANACEAE (1/1) & Couepia schottii Fritsch & C.Farney 3187 \\
\hline COMBRETACEAE (1/1) & Buchenavia kleinii Exell & C.Farney 3186 \\
\hline CONNARACEAE (1/1) & Connarus nodosus Baker & C.Farney 3250 \\
\hline EBENACEAE $(1 / 1)$ & Diospyros sp. & C.Farney 3195 \\
\hline ERYTHROXYLACEAE (1/1) & Erythroxylum pulchrum A.St.-Hil. & C.Farney 3183 \\
\hline \multirow[t]{5}{*}{ EUPHORBIACEAE (4/5) } & Algernonia obovata Müll.Arg. & C.Farney 3185 \\
\hline & Joannesia princeps Vell. & C.Farney 3182 \\
\hline & Phyllanthus aff. riedelianus Müll.Arg. & C.Farney 3184 \\
\hline & Sebastiania sp. & C.Farney 3243 \\
\hline & Indeterminada & C.Farney 3276 \\
\hline \multirow[t]{4}{*}{ FLACOURTIACEAE (3/4) } & Banara brasiliensis (Schott.) Benth. & C.Farney 3257 \\
\hline & Carpotroche brasiliensis (Raddi) A.Gray & C.Farney 3199 \\
\hline & Casearia oblongifolia Cambess. & C.Farney 3207 \\
\hline & Casearia sylvestris $\mathrm{Sw}$ & C.Farney 3205 \\
\hline GUTTIFERAE (1/1) & Rheedia brasiliensis (Mart.) Planch.\& Tr. & C.Farney 3180 \\
\hline \multirow[t]{3}{*}{ LAURACEAE (1/3) } & Ocotea complicata (Meissn.) Mez & C.Farney 3253 \\
\hline & Ocotea polyantha (Nees) Mez & C.Farney 3168 \\
\hline & Ocotea schottii (Meisn.) Mez & C.Farney 3166 \\
\hline \multirow[t]{4}{*}{ LEGUMINOSAE CAES. (13/15) } & Copaifera lucens Dwyer & C.Farney 3179 \\
\hline & Exostyles venusta Schott ex Spreng & C.Farney 3181 \\
\hline & Swartzia apetala Raddi var. apetala & C.Farney 3178 \\
\hline & Zollernia glabra (Spreng.) Yakovl. & C.Farney 3177 \\
\hline LEGUMINOSAE MIM. & $\begin{array}{l}\text { Albizia polycephala (Benth.) } \\
\text { Barneby \& Grimes }\end{array}$ & C.Farney 3171 \\
\hline
\end{tabular}




\begin{tabular}{|c|c|c|}
\hline Familia & Espécie & Coletor e $\mathbf{N}^{\circ}$ \\
\hline & Inga capitata Desv. & C.Farney 3174 \\
\hline & Inga fagifolia (L.) Benth. & C.Farney 3173 \\
\hline & Inga maritima Benth. & C.Farney 3172 \\
\hline & $\begin{array}{l}\text { Parapiptadenia pterosperma } \\
\text { (Benth.) Brenan }\end{array}$ & C.Farney 3170 \\
\hline & $\begin{array}{l}\text { Pseudopiptadenia contorta (DC.) } \\
\text { G.P.Lewis \& M.P.Lima }\end{array}$ & C.Farney 3169 \\
\hline \multirow[t]{5}{*}{ LEGUMINOSAE PAP. } & Andira legalis (Vell.) Toledo & C.Farney 3203 \\
\hline & Machaerium hirtum (Vell.) Stellfeld & C.Farney 3202 \\
\hline & Platymiscium floribundum Vogel & C.Farney 3176 \\
\hline & Poecilanthe falcata (Vell.) Heringer & C.Farney 3175 \\
\hline & Pterocarpus rohrii Vahl. & C.Farney 3198 \\
\hline LOGANIACEAE (1/1) & Strychnos gardneri A.DC. & C.Farney 3197 \\
\hline MALPIGHIACEAE (1/1) & Byrsonima sericea (A.Juss.) Griseb. in Mart & C.Farney 3208 \\
\hline MALVACEAE $(1 / 1)$ & Pavonia alnifolia A.St.-Hil. & C.Farney 3210 \\
\hline \multirow[t]{2}{*}{ MELIACEAE (1/2) } & Trichilia aff. pseudostipularis C.DC. & C.Farney 3244 \\
\hline & Trichilia aff. sylvatica C.DC. & C.Farney 3245 \\
\hline \multirow[t]{4}{*}{ MORACEAE (4/4) } & Brosimum guianense (Aubl.) C.Huber & C.Farney 3204 \\
\hline & Clarisia racemosa Ruiz \& Pav. & C.Farney 3246 \\
\hline & Coussapoa sp. & C.Farney 3200 \\
\hline & Ficus sp. & C.Farney 3201 \\
\hline \multirow[t]{20}{*}{ MYRTACEAE (8/21) } & Calycorectes sp. & C.Farney 3270 \\
\hline & Eugenia aff. crassiflora Kiaersk. & C.Farney 3264 \\
\hline & Eugenia bahiensis DC. & C.Farney 3269 \\
\hline & Eugenia brasiliensis Lam. & C.Farney 3271 \\
\hline & Eugenia candolleana DC. & C.Farney 3266 \\
\hline & Eugenia copacabanensis Kiaersk. & C.Farney 3263 \\
\hline & Eugenia neolanceolata Sobral & C.Farney 3261 \\
\hline & Eugenia olivacea Berg & C.Farney 3262 \\
\hline & Eugenia punicifolia (Kunth.) DC. & C.Farney 3273 \\
\hline & Eugenia rotundifolia Casar. & C.Farney 3265 \\
\hline & Eugenia schottiana O.Berg & C.Farney 3142 \\
\hline & Eugenia sp.1 & C.Farney 3259 \\
\hline & Eugenia sp.2 & C.Farney 3260 \\
\hline & Eugenia sp.3 & C.Farney 3211 \\
\hline & Gomidesia martiana O.Berg & C.Farney 3268 \\
\hline & Marlierea sp. & C.Farney 3214 \\
\hline & Marlierea tomentosa Camb. & C.Farney 3258 \\
\hline & Myrcia multiflora (Lam.) DC. & C.Farney 3272 \\
\hline & Myrciaria tenella (DC.) Berg. & C.Farney 3213 \\
\hline & Neomitranthes langsdorfii (O.Berg) Mattos & C.Farney 3140 \\
\hline
\end{tabular}




\begin{tabular}{|c|c|c|}
\hline Familia & Espécie & Coletor e $\mathbf{N}^{\circ}$ \\
\hline & Plinia ilhensis G.M.Barroso & C.Farney 3267 \\
\hline NYCTAGINACEAE (1/1) & Guapira opposita (Vell.) Reitz & C.Farney 3216 \\
\hline \multirow[t]{3}{*}{ OLACACEAE $(3 / 3)$} & Cathedra rubricaulis Miers. & C.Farney 3224 \\
\hline & Dulacia sp. & C.Farney 3274 \\
\hline & Schoepfia brasileinsis A.DC. & C.Farney 3167 \\
\hline OPILIACEAE (1/1) & Agonandra excelsa Griseb. & C.Farney 3232 \\
\hline \multirow[t]{2}{*}{ POLYGONACEAE (2/2) } & Coccoloba declinata (Vell.) Mart. & C.Farney 3248 \\
\hline & Ruprechtia lundii Meissner & C.Farney 3165 \\
\hline \multirow[t]{3}{*}{ RUBIACEAE (3/3) } & Alseis involuta K.Schum. & C.Farney 3217 \\
\hline & Coutarea hexandra (Jacq.) K.Schum. & C.Farney 3218 \\
\hline & Guettarda viburnoides Cham. \& Schlt. & C.Farney 3219 \\
\hline \multirow[t]{2}{*}{ RUTACEAE (2/2) } & Rauia aff. resinosa Nees \& Mart. & C.Farney 3225 \\
\hline & Zanthoxylum monogynum A.St.-Hil. & C.Farney 3227 \\
\hline \multirow[t]{5}{*}{ SAPINDACEAE $(3 / 5)$} & Allophylus puberulus Radlk. & C.Farney 3239 \\
\hline & Cupania racemosa (Vell.) Radlk. & C.Farney 3256 \\
\hline & Cupania sp.1 & C.Farney 3238 \\
\hline & Cupania sp.2 & C.Farney 3275 \\
\hline & Matayba guianensis (Aubl.) Radlk. & C.Farney 3240 \\
\hline \multirow[t]{9}{*}{ SAPOTACEAE (4/9) } & Chrysophyllum januariense Eichl. & C.Farney 3222 \\
\hline & Chrysophyllum lucentifolium Cronquist & C.Farney 3223 \\
\hline & Manilkara subsericea (Mart.) Dubard. & C.Farney 3229 \\
\hline & Pouteria grandiflora (A.DC.) Baehni & C.Farney 3230 \\
\hline & Pouteria lucumifolia (Reiss ex Mez) Penn. & C.Farney 3234 \\
\hline & Pouteria psammophila (Mart.) Radlk. & C.Farney 3233 \\
\hline & Pouteria reticulata (Engl.) Eyma & C.Farney 3231 \\
\hline & Pradosia lactescens (Vell.) Radlk. & C.Farney 3220 \\
\hline & Pradosia sp. & C.Farney 3221 \\
\hline SIMAROUBACEAE (1/1) & Simaba cuneata A.St.-Hil. \& Tul. & C.Farney 3237 \\
\hline TILIACEAE (1/1) & Luehea ochrophylla Mart. & C.Farney 3251 \\
\hline VERBENACEAE (1/1) & Vitex rufescens A.Juss. & C.Farney 3241 \\
\hline
\end{tabular}

floresta em regeneração. Por exemplo, as cinco espécies mais abundantes em ordem decrescente na amostragem (Tab. 3) Algernonia obovata, Pterocarpus rohrii, Pseudopiptadenia contorta, Guapira opposita e Alseis involuta distribuem respectivamente $61 \%, 31,9 \%, 30,2 \%, 31 \%$ e $37,9 \%$ dos indivíduos entre essas classes diamétricas. O DAP médio foi $11,6 \pm 7,2 \mathrm{~cm}$, e apenas $11,6 \%$ dos indivíduos apresentaram $\mathrm{DAP} \geq 20 \mathrm{~cm}$, sendo que cinco espécies e uma morfoespécie ocorreram exclusivamente a partir desta classe: Spondias venulosa, Byrsonima sericea, Dulacia sp., Tabebuia sp., Eugenia schottiana. Dentre as árvores com maiores diâmetros, destacaram-se os três maiores indivíduos: Spondias venulosa (DAP $=64,4 \mathrm{~cm}$ ), Pterocarpus rohrii (DAP $=62,1 \mathrm{~cm})$ e Couepia schottii $(\mathrm{DAP}=61,1 \mathrm{~cm})$.

Quando a análise considerou o critério de inclusão o DAS $\geq 5 \mathrm{~cm}$, a amostragem apresentou densidade de 1.574 indivíduos/ha. Entretanto 


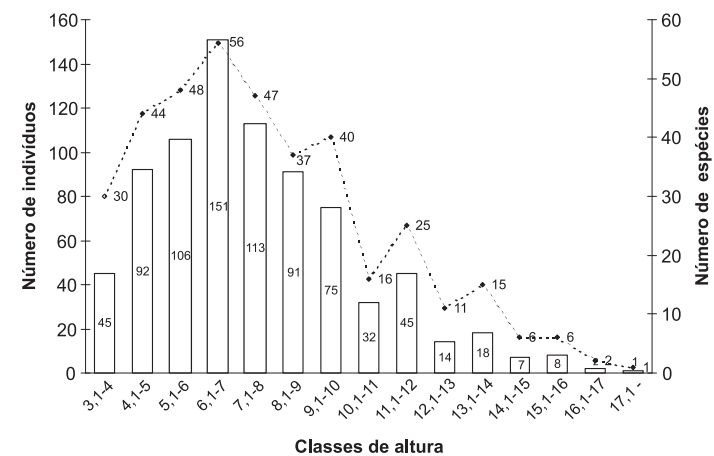

Figura 1 - Distribuição do número de indivíduos e espécies por classes de altura na floresta de restinga da Reserva Ecológica Estadual de Jacarepiá, RJ.

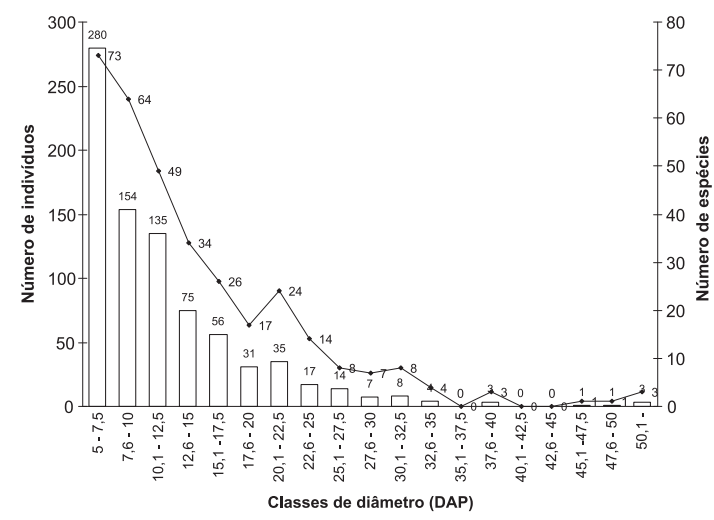

Figura 2 - Distribuição do número de indivíduos e espécies por classes de diâmetro a altura do peito (DAP) na floresta de restinga da Reserva Ecológica Estadual de Jacarepiá,RJ.

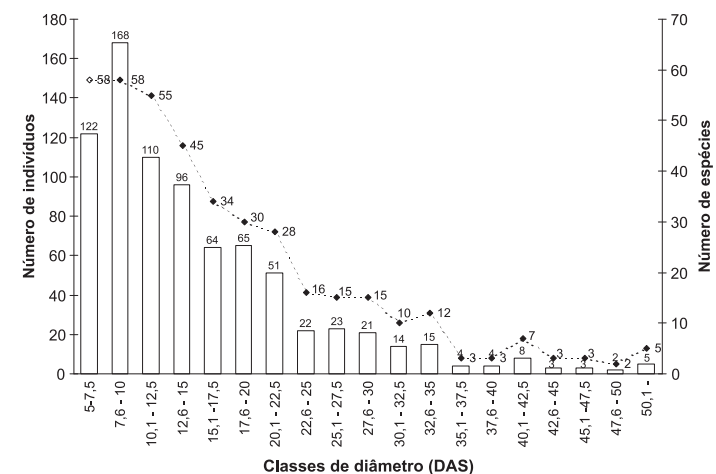

Figura 3 - Distribuição do número de indivíduos e espécies por classes de diâmetro a altura do solo (DAS) na floresta de restinga da Reserva Ecológica Estadual de Jacarepiá, RJ.
Tabela 2 - Famílias e respectiva riqueza de espécies (S) e abundância de indivíduos (Ni), com respectivos percentuais, na amostragem da floresta de restinga na Reserva Ecológica de Jacarepiá, Saquarema, RJ.

\begin{tabular}{lclll}
\hline Familias & $\mathbf{S}$ & $\mathbf{S \%}$ & $\mathbf{N i}$ & $\mathbf{\%}$ \\
\hline Myrtaceae & 21 & 19,0 & 65 & 8,1 \\
Leguminosae & 15 & 14,0 & 159 & 20,0 \\
Sapotaceae & 9 & 8,3 & 55 & 6,9 \\
Euphorbiaceae & 5 & 4,6 & 86 & 11,0 \\
Sapindaceae & 5 & 4,6 & 18 & 2,3 \\
Moraceae & 4 & 3,7 & 27 & 3,4 \\
Flacourtiaceae & 4 & 3,7 & 15 & 1,9 \\
Rubiaceae & 3 & 2,8 & 49 & 6,1 \\
Bombacaceae & 3 & 2,8 & 45 & 5,6 \\
Lauraceae & 3 & 2,8 & 29 & 3,6 \\
Olacaceae & 3 & 2,8 & 9 & 1,1 \\
Annonaceae & 2 & 1,9 & 31 & 3,9 \\
Rutaceae & 2 & 1,9 & 29 & 3,6 \\
Meliaceae & 2 & 1,9 & 24 & 3,0 \\
Anacardiaceae & 2 & 1,9 & 20 & 2,5 \\
Apocynaceae & 2 & 1,9 & 16 & 2,0 \\
Polygonaceae & 2 & 1,9 & 5 & 0,6 \\
Bignoniaceae & 2 & 1,9 & 2 & 0,3 \\
Nyctaginaceae & 1 & 0,9 & 29 & 3,6 \\
Simaroubaceae & 1 & 0,9 & 21 & 2,6 \\
Chrysobalanaceae & 1 & 0,9 & 11 & 1,4 \\
Erythroxylaceae & 1 & 0,9 & 10 & 1,3 \\
Opiliaceae & 1 & 0,9 & 8 & 1,0 \\
Guttiferae & 1 & 0,9 & 7 & 0,9 \\
Verbenaceae & 1 & 0,9 & 6 & 0,8 \\
Combretaceae & 1 & 0,9 & 5 & 0,6 \\
Malvaceae & 1 & 0,9 & 5 & 0,6 \\
Cactaceae & 1 & 0,9 & 4 & 0,5 \\
Ebenaceae & 1 & 0,9 & 2 & 0,3 \\
Capparaceae & 1 & 0,9 & 1 & 0,1 \\
Connaraceae & 1 & 0,9 & 1 & 0,1 \\
Indeterminada1 & 1 & 0,9 & 1 & 0,1 \\
Indeterminada2 & 1 & 0,9 & 1 & 0,1 \\
Indeterminada3 & 1 & 0,9 & 1 & 0,1 \\
Loganiaceae & 1 & 0,9 & 1 & 0,1 \\
Malpighiaceae & 1 & 0,9 & 1 & 0,1 \\
Tiliaceae & 1 & 0,9 & 1 & 0,1 \\
\hline & & & &
\end{tabular}


Tabela 3 - Parâmetros fitossociológicos a partir do DAP das espécies encontradas na floresta de restinga da Reserva Ecológica Estadual de Jacarepiá, Saquarema, RJ. (NI=número de indivíduos, De.Ab=densidade absoluta, De.Re=densidade relativa, Do.Ab=dominância absoluta Do.Re=dominância relativa, Fr.Ab=freqüência absoluta, Fr.Re=freqüência relativa, VI=valor de importância, VC=valor de cobertura, Alt.mi=altura

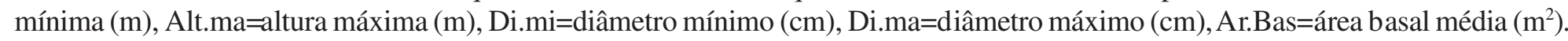

\begin{tabular}{|c|c|c|c|c|c|c|c|c|c|c|c|c|c|c|}
\hline Especie & NI & De.Ab & De.Re & Do.Ab & Do.Re & Fr:Ab & Fr.Re & VI & VC & Alt.mi & Alt.ma & Di.mi & Di.ma & Ar:Bas \\
\hline Algernonia obovata & 69 & 137,8 & 8,63 & 1,3066 & 5,60 & 27,0 & 7,21 & 21,43 & 14,22 & 4,0 & 11 & 5,1 & 20,8 & 0,6545 \\
\hline Pterocarpus rohrii & 47 & 93,8 & 5,88 & 2,0426 & 8,75 & 20,5 & 5,47 & 20,1 & 14,63 & 5,0 & 17 & 5,4 & 49,6 & 1,0231 \\
\hline Pseudopiptadenia contorta & 43 & 85,8 & 5,38 & 1,6725 & 7,17 & 19,5 & 5,21 & 17,75 & 12,54 & 4,0 & 16 & 5,1 & 37,9 & 0,8377 \\
\hline Guapira opposita & 29 & 57,9 & 3,63 & 1,1779 & 5,05 & 14,0 & 3,74 & 12,41 & 8,67 & 4,0 & 14 & 5,1 & 32,2 & 0,5900 \\
\hline Alseis involuta & 29 & 57,9 & 3,63 & 0,9539 & 4,09 & 13,0 & 3,47 & 11,18 & 7,71 & 4,0 & 14 & 5,1 & 26,4 & 0,4778 \\
\hline Simaba cuneata & 21 & 41,9 & 2,63 & 1,1675 & 5,00 & 10,0 & 2,67 & 10,3 & 7,63 & 5,5 & 14 & 6,0 & 32,5 & 0,5848 \\
\hline Astronium graveolens & 19 & 37,9 & 2,38 & 0,6521 & 2,79 & 8,0 & 2,14 & 7,31 & 5,17 & 5,0 & 12 & 5,1 & 30,2 & 0,3266 \\
\hline Eriotheca pentaphylla & 14 & 28,0 & 1,75 & 0,8413 & 3,60 & 6,5 & 1,74 & 7,09 & 5,35 & 7,0 & 14 & 6,4 & 31,5 & 0,4214 \\
\hline Trichilia aff sylvatica & 16 & 31,9 & 2,00 & 0,6719 & 2,88 & 7,5 & 2,00 & 6,88 & 4,88 & 4,5 & 16 & 5,1 & 50,0 & 0,3366 \\
\hline Ocotea complicata & 19 & 37,9 & 2,38 & 0,4854 & 2,08 & 8,5 & 2,27 & 6,72 & 4,45 & 5,0 & 14 & 5,1 & 31,9 & 0,2432 \\
\hline Cоиеріa schottii & 11 & 22,0 & 1,38 & 0,8812 & 3,78 & 5,0 & 1,34 & 6,49 & 5,15 & 5,0 & 16 & 5,4 & 61,1 & 0,4414 \\
\hline Brosimum guianense & 22 & 43,9 & 2,75 & 0,1697 & 0,73 & 10,5 & 2,80 & 6,28 & 3,48 & 4,0 & 9,0 & 5,1 & 12,4 & 0,0850 \\
\hline Rauia aff resinosa & 23 & 45,9 & 2,88 & 0,1545 & 0,66 & 10,0 & 2,67 & 6,21 & 3,54 & 2,5 & 8,0 & 5,1 & 9,9 & 0,0774 \\
\hline Pouteria grandiflora & 21 & 41,9 & 2,63 & 0,2255 & 0,97 & 9,5 & 2,54 & 6,13 & 3,59 & 4,0 & 10 & 5,1 & 14,2 & 0,1129 \\
\hline Bombacopsis stenopetala & 14 & 28,0 & 1,75 & 0,5308 & 2,27 & 7,0 & 1,87 & 5,89 & 4,02 & 4,0 & 15 & 5,1 & 45,8 & 0,2659 \\
\hline Chrysophyllum lucentifolium & 14 & 28,0 & 1,75 & 0,5013 & 2,15 & 7,0 & 1,87 & 5,77 & 3,9 & 4,0 & 12 & 5,1 & 30,9 & 0,2511 \\
\hline Albizia polycephala & 17 & 33,9 & 2,13 & 0,2931 & 1,26 & 8,5 & 2,27 & 5,65 & 3,38 & 7,0 & 12 & 5,7 & 15,3 & 0,1468 \\
\hline Guettarda viburnoides & 14 & 28,0 & 1,75 & 0,4597 & 1,97 & 6,5 & 1,74 & 5,46 & 3,72 & 5,0 & 10,5 & 5,1 & 27,7 & 0,2303 \\
\hline Duguetia sessilis & 17 & 33,9 & 2,13 & 0,2328 & 1,00 & 8,5 & 2,27 & 5,39 & 3,12 & 4,0 & 10 & 5,1 & 13,9 & 0,1166 \\
\hline Pseudobombax grandiflorum & 17 & 33,9 & 2,13 & 0,2143 & 0,92 & 8,5 & 2,27 & 5,31 & 3,04 & 4,0 & 10 & 5,1 & 16,9 & 0,1073 \\
\hline Oxandra nitida & 14 & 28,0 & 1,75 & 0,3123 & 1,34 & 6,5 & 1,74 & 4,82 & 3,09 & 5,0 & 14 & 5,4 & 20,0 & 0,1564 \\
\hline Aspidosperma parvifolium & 12 & 24,0 & 1,50 & 0,3155 & 1,35 & 6,0 & 1,60 & 4,45 & 2,85 & 5,0 & 13 & 5,1 & 21,8 & 0,1580 \\
\hline Erythroxylum pulchrum & 10 & 20,0 & 1,25 & 0,4375 & 1,87 & 4,0 & 1,07 & 4,19 & 3,12 & 6,0 & 12 & 5,4 & 37,6 & 0,2191 \\
\hline Eugenia $\mathrm{sp.3}$ & 12 & 24,0 & 1,50 & 0,1903 & 0,82 & 6,0 & 1,60 & 3,92 & 2,32 & 5,0 & 12 & 5,4 & 14,3 & 0,0953 \\
\hline
\end{tabular}




\begin{tabular}{|c|c|c|c|c|c|c|c|c|c|c|c|c|c|c|}
\hline Especie & NI & De.Ab & De.Re & Do.Ab & Do.Re & Fr.Ab & Fr.Re & VI & VC & Alt.mi & Alt.ma & Di.mi & Di.ma & Ar.Bas \\
\hline Cathedra rubricaulis & 7 & 14 & 0,88 & 0,4503 & 1,93 & 3,5 & 0,93 & 3,74 & 2,80 & 7,0 & 13 & 9,2 & 27,4 & 0,2255 \\
\hline Exostyles venusta & 7 & 14 & 0,88 & 0,3751 & 1,61 & 3,5 & 0,93 & 3,42 & 2,48 & 7,5 & 15 & 10,5 & 27,7 & 0,1879 \\
\hline Inga fagifolia & 10 & 20 & 1,25 & 0,1516 & 0,65 & 5,0 & 1,34 & 3,23 & 1,90 & 3,0 & 14 & 6,0 & 17,8 & 0,0759 \\
\hline Agonandra excelsa & 8 & 16 & 1,00 & 0,2889 & 1,24 & 3,5 & 0,93 & 3,17 & 2,24 & 4,0 & 16 & 5,4 & 28,3 & 0,1447 \\
\hline Eugenia sp.1 & 8 & 16 & 1,00 & 0,2292 & 0,98 & 4,0 & 1,07 & 3,05 & 1,98 & 4,0 & 15 & 5,1 & 22,3 & 0,1148 \\
\hline Neomitranthes langsdorfii & 8 & 16 & 1,00 & 0,1913 & 0,82 & 4,0 & 1,07 & 2,89 & 1,82 & 4,0 & 22 & 5,1 & 22,6 & 0,0958 \\
\hline Allophylus puberulus & 9 & 18 & 1,13 & 0,0839 & 0,36 & 4,5 & 1,20 & 2,69 & 1,48 & 3,0 & 7 & 5,7 & 13,3 & 0,0420 \\
\hline Parapiptadenia pterosperma & 4 & 8 & 0,50 & 0,3831 & 1,64 & 2,0 & 0,53 & 2,68 & 2,14 & 6,0 & 12 & 5,7 & 38,5 & 0,1919 \\
\hline Phyllanthus aff riedelianus & 9 & 18 & 1,13 & 0,0792 & 0,34 & 4,5 & 1,20 & 2,67 & 1,46 & 4,0 & 6 & 5,1 & 10 & 0,0397 \\
\hline Carpotroche brasiliensis & 7 & 14 & 0,88 & 0,2240 & 0,96 & 3,0 & 0,80 & 2,64 & 1,83 & 5,5 & 14 & 8,3 & 21,3 & 0,1122 \\
\hline Clarisia racemosa & 3 & 6 & 0,38 & 0,3844 & 1,65 & 1,5 & 0,40 & 2,42 & 2,02 & 10,0 & 14 & 11,5 & 34,4 & 0,1925 \\
\hline Trichilia aff pseudostipularis & 8 & 16 & 1,00 & 0,1036 & 0,44 & 3,5 & 0,93 & 2,38 & 1,44 & 4,0 & 10 & 5,7 & 18,4 & 0,0519 \\
\hline Vitex rufescens & 6 & 12 & 0,75 & 0,1421 & 0,61 & 3,0 & 0,80 & 2,16 & 1,36 & 7,0 & 10 & 7,6 & 15,9 & 0,0712 \\
\hline Poecilanthe falcata & 5 & 10 & 0,63 & 0,1893 & 0,81 & 2,5 & 0,67 & 2,10 & 1,44 & 7,0 & 13 & 8,9 & 26,4 & 0,0948 \\
\hline Rheedia brasiliensis & 7 & 14 & 0,88 & 0,0576 & 0,25 & 3,5 & 0,93 & 2,06 & 1,12 & 4,0 & 7 & 5,1 & 10,5 & 0,0289 \\
\hline Machaerium hirtum & 6 & 12 & 0,75 & 0,1157 & 0,5 & 3,0 & 0,80 & 2,05 & 1,25 & 5,0 & 16 & 7,3 & 17,5 & 0,0579 \\
\hline Chrysophyllum januariense & 6 & 12 & 0,75 & 0,1136 & 0,49 & 3,0 & 0,80 & 2,04 & 1,24 & 6,0 & 12 & 5,4 & 20,7 & 0,0569 \\
\hline Ocotea polyantha & 6 & 12 & 0,75 & 0,0531 & 0,23 & 3,0 & 0,80 & 1,78 & 0,98 & 6,0 & 9 & 5,4 & 9,5 & 0,0266 \\
\hline Coutarea hexandra & 6 & 12 & 0,75 & 0,0392 & 0,17 & 3,0 & 0,80 & 1,72 & 0,92 & 6,0 & 8 & 5,1 & 7,3 & 0,0196 \\
\hline Eugenia copacabanensis & 4 & 8 & 0,50 & 0,1548 & 0,66 & 2,0 & 0,53 & 1,70 & 1,16 & 4,0 & 17 & 5,1 & 29 & 0,0775 \\
\hline Zollernia glabra & 4 & 8 & 0,50 & 0,1530 & 0,66 & 2,0 & 0,53 & 1,69 & 1,16 & 4,0 & 11 & 10,4 & 22,9 & 0,0766 \\
\hline Zanthoxylum monogynum & 6 & 12 & 0,75 & 0,0280 & 0,12 & 3,0 & 0,80 & 1,67 & 0,87 & 4,0 & 7 & 5,1 & 5,7 & 0,0140 \\
\hline Pouteria lucumifolia & 3 & 6 & 0,38 & 0,1954 & 0,84 & 1,5 & 0,40 & 1,61 & 1,21 & 8,0 & 11 & 13,8 & 24 & 0,0979 \\
\hline Pradosia lactescens & 4 & 8 & 0,50 & 0,1110 & 0,48 & 2,0 & 0,53 & 1,51 & 0,98 & 6,5 & 9 & 10,5 & 15,9 & 0,0556 \\
\hline Pavonia alnifolia & 5 & 10 & 0,63 & 0,0420 & 0,18 & 2,5 & 0,67 & 1,47 & 0,80 & 5,0 & 7 & 5,1 & 9,4 & 0,0210 \\
\hline
\end{tabular}




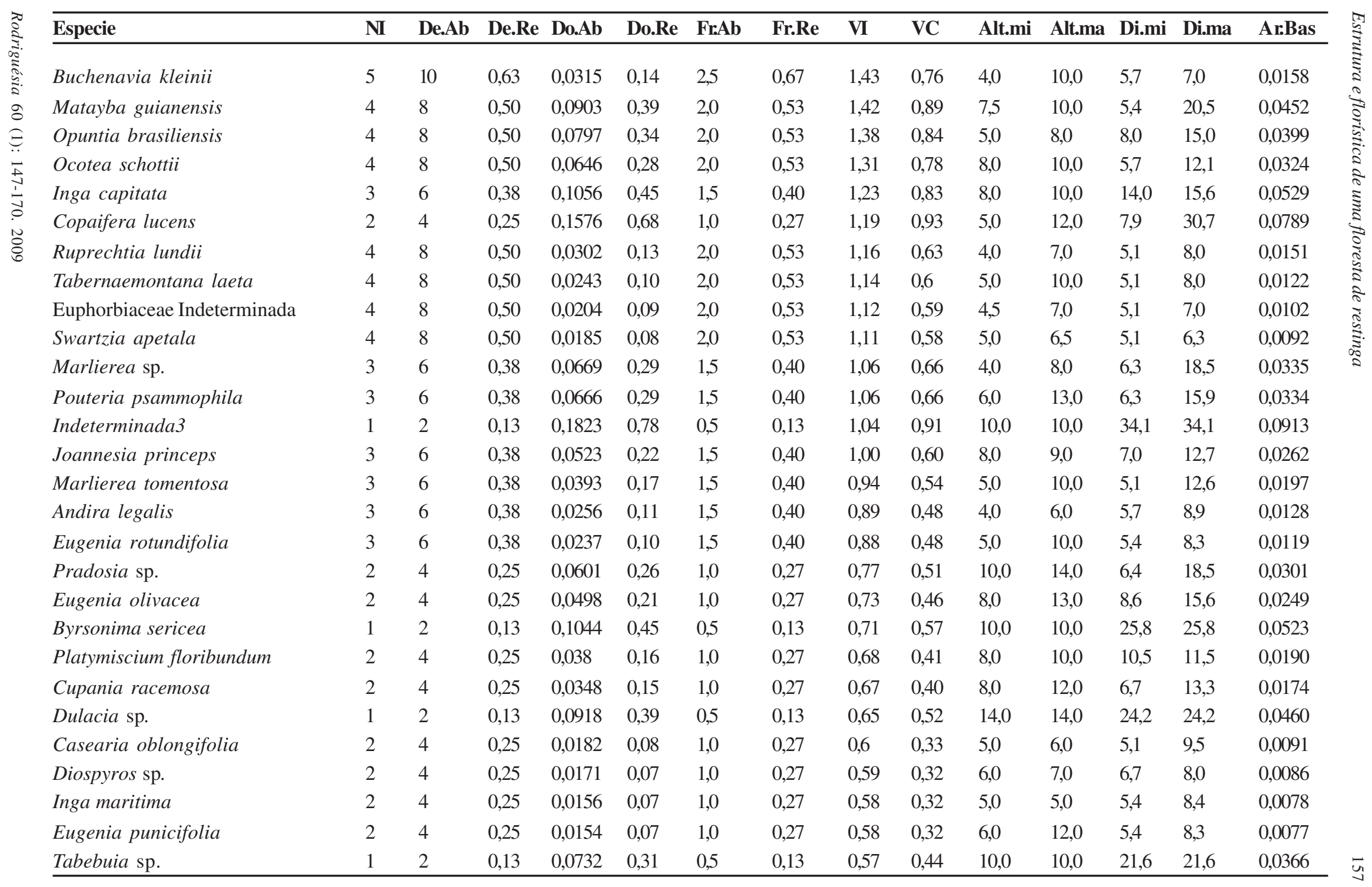




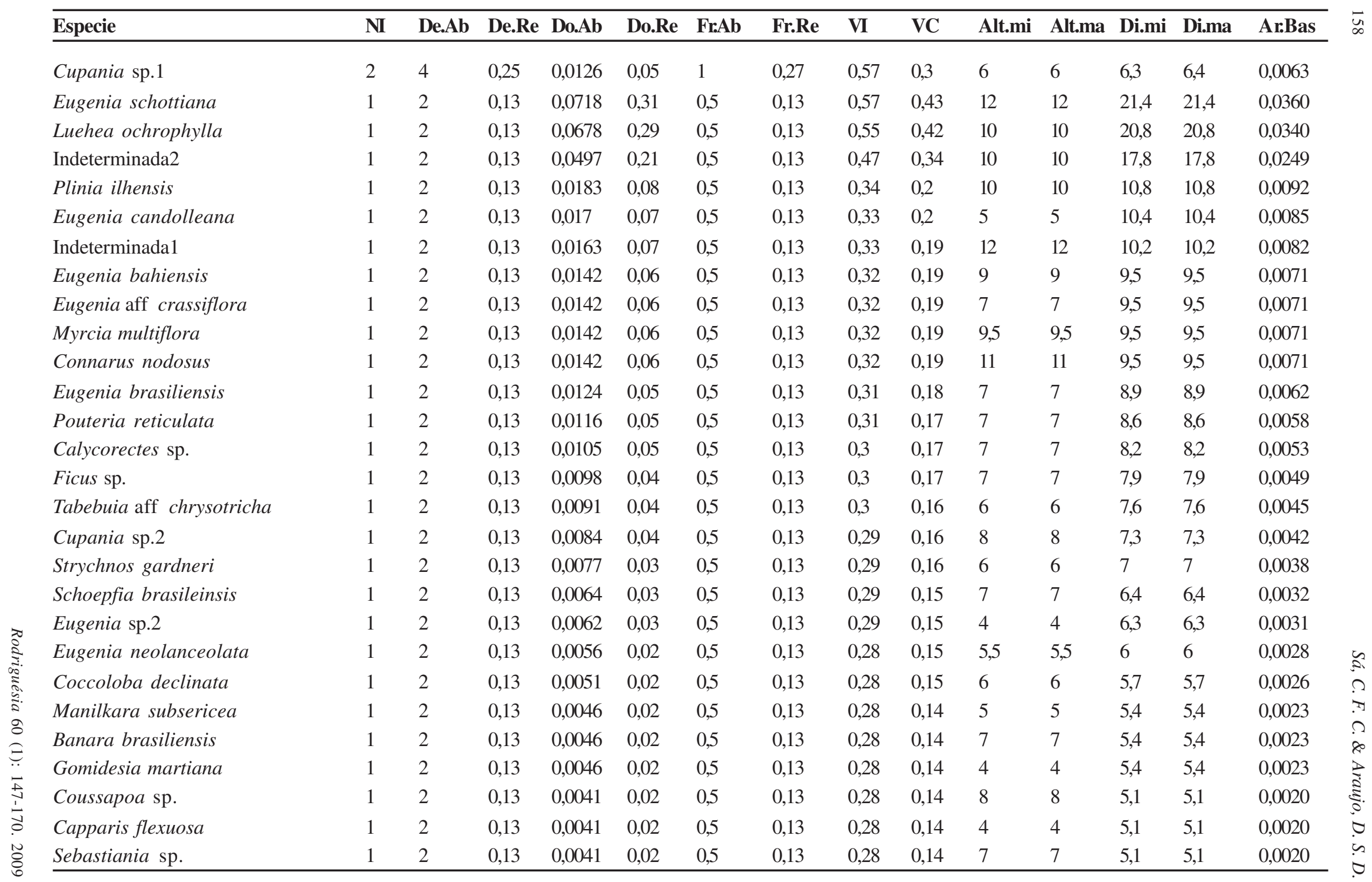


a área basal aumentou em 59,4\%, ou seja, $39,2 \mathrm{~m}^{2} /$ ha. O DAS médio foi de $15,3 \pm 9,1 \mathrm{~cm}$. As espécies que apresentaram os maiores troncos engrossados na base foram Couepia schottii $(63,4 \mathrm{~cm})$, Spondias venulosa $(56,3$ $\mathrm{cm})$, Copaifera lucens (56 cm), Trichilia sylvatica $(55,1 \mathrm{~cm})$ e Eriotheca pentaphylla (51,6 cm).

De acordo com os parâmetros fitossociológicos de densidade, dominância e frequência obtidos para a floresta de Jacarepiá, utilizando a análise através do DAP (Tab. 3) o conjunto das 10 primeiras espécies concentram 40,4\% do valor de importância (VI). O destaque para Algernonia obovata como espécie de maior VI se deveu principalmente às suas elevadas densidade e frequência. Quando os VIs das espécies são analisados em relação ao DAS, as 10 espécies com maiores valores de importância contabilizaram 40,6\% deste parâmetro. Novamente Algernonia obovata destacou-se como espécie de maior VI em função de elevadas densidade e freqüência. $\mathrm{Na}$ análise comparativa entre as 10 espécies mais importantes em VI, em relação ao DAP e DAS, as nove primeiras espécies da Tab. 3 são prevalentes nas duas análises. A espécie Brosimum guianense substitui Trichilia sylvatica ao se considerar a análise através do DAS. A tabela com análise de dados a partir do DAS pode ser obtida com os autores.

Os troncos múltiplos, quando analisados a partir das mensurações ao nível do solo (DAS) são encontrados em 20 espécies (28 indivíduos, 69 troncos) com destaque para Pouteria grandiflora que exibe esta característica em cerca de $24 \%$ do total de indivíduos encontrados na amostragem. Quando as mensurações são tomadas a 1,30 m do solo (DAP) são encontradas em 48 espécies (104 indivíduos, 267 troncos) com destaque para as seguintes espécies e suas respectivas porcentagens do total de indivíduos: Algernonia obovata (16\%), Pterocarpus rohrii (19\%), Simaba cuneata (33\%), Alseis involuta (17\%), Pseudopiptadenia contorta (12\%), Ocotea complicata (26\%) e Pouteria grandiflora $(23 \%)$.

\section{Discussão \\ Riqueza, Diversidade e Similaridade}

As famílias Myrtaceae, Leguminosae e Sapotaceae foram as mais ricas na floresta de Jacarepiá; as duas primeiras são citadas como mais ricas em estudos florísticos e fitogeográficos para a Floresta Atlântica (Moriet al. 1983; Lima 2000; Oliveira-Filho \& Fontes 2000; Amorim et al. 2005) e para as restingas fluminenses e capixabas (Araujo 2000; Pereira \& Araujo 2000). Nas florestas de restinga do sul e sudeste, em estudos de estrutura, a riqueza dessas famílias foi relacionada a latitude e ao tipo de floresta, se inundável ou não (Tab. 4).

No litoral sul a riqueza de espécies em Leguminosae é marcadamente menor (Tab. 4), tanto em áreas com ou sem inundação, aumenta do litoral sudeste a partir de Ubatuba (Picinguaba) para o estado do Rio de Janeiro, e na região do Centro de Diversidade Vegetal de Cabo Frio, onde o clima é mais seco, atinge máxima riqueza em relação ao trecho litorâneo sul/sudeste. Gentry (1995) aponta esta família como das mais ricas em áreas com estacionalidade climática. A riqueza de espécies em Myrtaceae é maior mesmo em áreas do litoral sul e sudeste com e sem inundação, inclusive em área perturbada no estado do Rio de Janeiro. Nas demais áreas do estado do Rio de Janeiro, a riqueza dessa família é bem marcada, e em Jacarepiá deve ser ressaltado que o critério de inclusão adotado (DAP $\geq 5$ ) foi muito mais excludente que o do estudo de Fernandes (2005) onde a riqueza foi pouco maior. A família Sapotaceae apresentou riqueza destacada nas áreas sem inundação do Centro de Diversidade Vegetal de Cabo Frio e no Espírito Santo. No litoral sul, a família Sapotaceae, embora representada por apenas uma espécie nos estudos de Silva et al. (1994), Waechter et al. (2000) e Guedes et al. (2006) (sendo essas Pouteria beaurepaurei, Sideroxylon obtusifolium e Manilkara subsericea, respectivamente), foi a mais importante na estrutura dessas áreas. As demais famílias em Jacarepiá apresentaram riquezas e abundâncias variáveis, com 26 famílias apresentando de uma a duas espécies, ressaltando-se a ausência das 
Tabela 4 - Distribuição da riqueza de espécies das três famílias mais ricas deste estudo (Myrtaceae, Leguminosae e Sapotaceae) em comparação com outros levantamentos em áreas de floresta de restinga no litoral sul e sudeste do Brasil.

\begin{tabular}{|c|c|c|c|c|c|c|c|c|c|c|c|}
\hline \multirow[t]{2}{*}{ Referência } & \multirow[t]{2}{*}{ Município } & \multirow[t]{2}{*}{ Substrato } & \multirow[t]{2}{*}{ Critério } & \multirow[t]{2}{*}{$\mathbf{T}$} & \multirow[t]{2}{*}{$\mathbf{S}$} & \multicolumn{2}{|c|}{ Myrtaceae } & \multicolumn{2}{|c|}{ Leguminosae } & \multicolumn{2}{|c|}{ Sapotaceae } \\
\hline & & & & & & Spp. & indiv.\% & spp. & indiv. \% & spp. & indiv. \% \\
\hline Este estudo & Saquarema/RJ & NI & $\mathrm{DAP} \geq 5(++)$ & 800 & 108 & 21 & 8,1 & 15 & 19,8 & 9 & 1,1 \\
\hline Assis et al. 2004 & Guarapari/ES & NI & $\mathrm{DAP} \geq 5(+)$ & 2.039 & 92 & 20 & 27,5 & 5 & 4,3 & 9 & 17,1 \\
\hline Assumpção \& Nascimento 2000 & S.J.Barra/RJ $(*)$ & NI & $\mathrm{DAS} \geq 2,5(+)$ & 380 & 37 & 10 & 15,0 & 2 & 0,7 & 2 & 5,0 \\
\hline Barros 2000 & Macaé/RJ & I & $\mathrm{DAP} \geq 5(+)$ & 827 & 49 & 7 & 9,0 & 4 & 1,2 & 1 & 2,5 \\
\hline Oliveira 2000 & Macaé/RJ & I & $\mathrm{DAP} \geq 5(+)$ & 938 & 45 & 5 & 9,8 & 4 & 2,7 & 1 & 0,1 \\
\hline Fernandes 2005 & Cabo Frio/RJ & NI & $\mathrm{DAP} \geq 2,5(+)$ & 1.127 & 158 & 21 & 5,6 & 18 & 12,4 & 8 & 3,9 \\
\hline Rezende 2004 & Cabo Frio/RJ & NI & $\mathrm{DAP} \geq 2,5(+)$ & 428 & 108 & 13 & 8,4 & 12 & 6,7 & 3 & 0,7 \\
\hline Fernandes 2002 & A. dos Búzios/RJ & NI & $\mathrm{DAP} \geq 2,5(+)$ & 366 & 74 & 15 & 21,0 & 6 & 7,1 & 3 & 3,0 \\
\hline Lobão \& Kurtz 2000 & A. dos Búzios/RJ & NI & $\mathrm{DAP} \geq 2,5(+)$ & 300 & 26 & 3 & 9,3 & 2 & 5,3 & 1 & 0,6 \\
\hline Fonseca-Kruel et al. 2009 & Arraial do Cabo/RJ & NI & $\mathrm{DAP} \geq 2,5(+)$ & 296 & 41 & 3 & 15,8 & 4 & 7,0 & 1 & 8,4 \\
\hline Sá 2002 & Saquarema/RJ $(*)$ & $\mathrm{NI}$ & $\mathrm{DAS} \geq 2,5(+)$ & 553 & 102 & 7 & 1,2 & 10 & 6,8 & 4 & 3,4 \\
\hline Cesar \& Monteiro 1995 & Ubatuba/SP & I & $\mathrm{DAP} \geq 4,8(+)$ & 996 & 74 & 19 & 25,5 & 7 & 3,8 & 0 & 0,0 \\
\hline Guedes et al. 2006 & Bertioga (1)/SP & I & $\mathrm{DAP} \geq 3,2(+)$ & 476 & 65 & 15 & 10,7 & 3 & 1,6 & 1 & 5,6 \\
\hline Guedes et al. 2006 & Bertioga (2)/SP & NI & $\mathrm{DAP} \geq 5,2(+)$ & 417 & 67 & 18 & 14,8 & 3 & 1,9 & 1 & 2,4 \\
\hline Sugiyama 1998 & Ilha do Cardoso/SP & I & $\mathrm{DAP} \geq 2,5(+)$ & 867 & 31 & 9 & 11,9 & 1 & 1,7 & 1 & 0,3 \\
\hline Silva et al. 1994 & Ilha do Mel/PR & $\mathrm{NI} / \mathrm{I}$ & $\mathrm{DAP} \geq 5(+)$ & 1.510 & 53 & 19 & 19,0 & 3 & 0,7 & 1 & 1,9 \\
\hline Dillenburg et al. 1992 & Emboaba/RS & NI & $\mathrm{DAP} \geq 5(++)$ & 180 & 15 & 2 & 21,1 & 0 & 0,0 & 2 & 6,6 \\
\hline Waechter et al. 2000 & Viamão/RS & NI & $\mathrm{DAP} \geq 10++)$ & 240 & 24 & 4 & 7,5 & 2 & 0,0 & 3 & 21,6 \\
\hline Dornelles \& Waechter 2004 & Lagoa do Peixe/RS & I & $\mathrm{DAP} \geq 5(++)$ & 240 & 21 & 4 & 30,4 & 0 & 0,0 & 0 & 0,0 \\
\hline Waecther \& Jarenkow 1998 & Taim/RS & I & $\mathrm{DAP} \geq 10++)$ & 120 & 12 & 4 & 39,1 & 1 & 26,6 & 1 & 2,5 \\
\hline
\end{tabular}


famílias Arecaceae e Melastomataceae no presente estudo, que são importantes na estrutura de outras florestas de restinga do litoral sul (Dornelles \& Waechter 2004) e sudeste (César \& Monteiro 1995; Guedes et al. 2006).

Quando a floresta de Jacarepiá é comparada a outros estudos de estrutura realizados em trechos da floresta atlântica de terras baixas do RJ, mostra-se mais rica em espécies de Myrtaceae e Leguminosae do que nos trechos estudados por Peixoto et al. (2005) em Guaratiba e por Carvalho et al. (2007) em Rio Bonito, e muito mais rica em espécies de Myrtaceae que em São Francisco do Itabapoana (Silva \& Nascimento 2001 - 8 spp.) e Campos dos Goytacazes (Carvalho et al. 2006 - 10 spp.). Entretanto, tal comparação mostra relativa equivalência para ambas as famílias para áreas de floresta baixo montana (350 m.s.m. - Moreno et al. 2003; 200 m.s.m., Kurtz \& Araujo 2000) em áreas próximas ao maciço da Serra do Mar.

A riqueza total de espécies arbóreas das famílias Leguminosae, Myrtaceae e Sapotaceae para esta área de estudo registrada inicialmente por Sá (1992) e revisadas por Araujo et al. (2009), é de respectivamente 33,25 e 10 espécies. Neste estudo, encontramos respectivamente 45,84 e $90 \%$ das espécies arbóreas dessas famílias, o que pode ser explicado pela aplicação do método de quadrantes, que é muito mais exploratório do que método de parcelas fixas (Martins 1991), podendo englobar espécies com distintos padrões de distribuição espacial. Assim podemos afirmar, até o momento, que as florestas de restinga do Centro de Diversidade Vegetal de Cabo Frio registram a maior riqueza de espécies das famílias Myrtaceae, Leguminosae e Sapotaceae já encontrada em estudos sobre estrutura dessas florestas no litoral sul e sudeste (Tab. 4), bem como registram o maior índice de diversidade H' (Tab. 5) desses trechos litorâneos.

$\mathrm{Na}$ floresta de Jacarepiá as 15 espécies de maior VI compõe 50\% do VI total, muito similar a área não inundável em Guarapari/ES (Assis et al. 2004) onde 14 espécies compõe $50 \%$ do VI total, indicando uma floresta de estrutura oligárquica. Para algumas florestas com baixa riqueza de espécies, um número ainda menor de espécies mantém a estrutura oligárquica, seja em função do ambiente

Tabela 5 - Síntese de dados estruturais e florísticos para áreas de floresta de restinga estudadas no estado do Rio de Janeiro

\begin{tabular}{|c|c|c|c|c|c|c|c|c|c|}
\hline Referência & Município & $\begin{array}{c}\text { Critério } \\
\text { mínimo } \\
(\mathrm{cm})\end{array}$ & $\begin{array}{c}\text { Area } \\
\text { (ha) }\end{array}$ & Indivíduos & Espécies & H' & $\mathbf{J}$ & $\begin{array}{c}\text { Densidade } \\
\text { (Ind/ha) }\end{array}$ & $\begin{array}{c}\text { Area } \\
\text { Basal } \\
\left(\mathrm{m}^{2} / \mathrm{ha}\right) \\
\end{array}$ \\
\hline Presente Estudo & Saquarema & $\geq 5$ & $0.5^{* *}$ & 800 & 108 & 4.06 & 0,87 & 1.597 & 23,3 \\
\hline $\begin{array}{l}\text { Assumpção \& } \\
\text { Nascimento (2000) }\end{array}$ & S. J.da Barra & $\geq 2.5^{*}$ & 0.09 & 380 & 37 & 2.81 & 0,78 & 4.222 & 32.6 \\
\hline Oliveira (2000) & Macaé & $\geq 5$ & 0.5 & 938 & 45 & 2.79 & 0,73 & 1.876 & 32.9 \\
\hline Fernandes (2005) & Cabo Frio & $\geq 2.5$ & 0.2 & 1.127 & 158 & 4.2 & 0,83 & 5.635 & 35.2 \\
\hline Rezende (2004) & Cabo Frio & $\geq 2.5$ & 0.1 & 414 & 108 & 4.0 & - & 4.140 & 32.1 \\
\hline Fernandes (2002) & A. dos Búzios & $\geq 2.5$ & 0.1 & 357 & 72 & 3.59 & 0,83 & 3.570 & 30 \\
\hline Lobão \& Kurtz (2000) & A. dos Búzios & $\geq 2.5$ & 0.1 & 312 & 26 & 2.52 & 0,76 & 3.120 & 21.8 \\
\hline $\begin{array}{l}\text { Fonseca-Kruel } \\
\text { et al. } 2009\end{array}$ & Arraial do Cabo & $\geq 2.5$ & 0.1 & 296 & 41 & 2.69 & 0,73 & 2.960 & 43.9 \\
\hline Sá(2002) & Saquarema & $\geq 2.5^{*}$ & 0.2 & 553 & 102 & - & - & 2.765 & 11,9 \\
\hline Araújo et al (1997) & Angra dos Reis & $\geq 2.5^{*}$ & 0,07 & 105 & 18 & - & - & 1.400 & 3,51 \\
\hline
\end{tabular}

* diâmetros tomados a altura do solo (DAS) ** estudo realizado com método de Ponto Quadrantes, área equivalente da amostra de acordo com o programa Params 2.2 (Shepherd 2006) 
inundável (Dornelles \& Waechter 2004; Sztutman \& Rodrigues 2002) ou submetidas a algum distúrbio (Assumpção \& Nascimento 2000), ou manejo seletivo (Fonseca-Kruel et al. 2009, neste volume) onde quatro espécies concentram mais de $50 \%$ deste parâmetro.

As dez espécies mais importantes em VI encontradas em nosso estudo, comparadas com as dez espécies igualmente importantes em outros estudos de estrutura de florestas de restinga do litoral sul e sudeste (Tab. 4), indicam que apenas três espécies foram prevalentes: Guapira opposita, Eriotheca pentaphylla e Pterocarpus rohrii. A primeira espécie foi citada para seis florestas; é das mais prevalentes em estudos de abundância e constância para a Floresta Atlântica do estado de São Paulo (Scudeller et al. 2001) e também considerada uma espécie generalista por Oliveira-Filho \& Fontes (2000) para a floresta atlântica do sudeste. Com relação a Eriotheca pentaphylla, esta apresentou-se importante nos estudos de São Paulo ao Espírito Santo, em áreas livres de inundação, evidenciando a seletividade para ambientes sem encharcamento. Por fim, Pterocarpus rohrii foi a espécie mais importante da amostragem de Fernandes (2005) em Cabo Frio, e também das mais importantes na avaliação da estrutura de trechos severamente perturbados da floresta de Jacarepiá estudada seis anos após o distúrbio por Sá (1996, 2002). Sua importância foi relacionada a sua capacidade de rebrota, inferida a partir de evidências de elevado número de troncos múltiplos na floresta adjacente sem perturbação (19\% dos indivíduos, este estudo).

Além dessas três espécies, um conjunto de outras nove (Casearia sylvestris, Coussapoa microcarpa, Eugenia brasiliensis, Eugenia neolanceolata, Manilkara subsericea, Marlierea tomentosa, Matayba guianensis, Myrcia multiflora e Rheedia brasiliensis), todas com baixos valores de importância em Jacarepiá, também ocorreram em algumas áreas entre os estados do Rio Grande do Sul e Espírito
Santo, algumas inclusive entre as dez espécies com maiores valores de importância. Destacase entre essas Myrcia multiflora, que foi um das espécies mais prevalentes nos levantamentos do Rio Grande do Sul ao Rio de Janeiro, inclusive com altos valores de importância em alguns casos.

Esses dados demonstram a heterogeneidade florística e estrutural dessas florestas de distribuição fragmentada naturalmente em função dos diferentes tipos de depósitos litorâneos, associados a complexidade geomorfológica encontrada ao longo do litoral sul e sudeste que se estende por cerca de 3.000 $\mathrm{km}$, onde também há heterogeneidade climática.

Há pouca similaridade entre a área estudada e as demais áreas de restinga situadas entre o Rio Grande do Sul (32 $30^{\circ}$ ') e São Paulo $\left(23^{\circ} 21^{\prime}\right)$ com ou sem inundação (Tab. 6) e mesmo entre algumas das áreas situadas no estado do Rio de Janeiro com ou sem inundação. As áreas mais similares, ainda que algumas abaixo de $25 \%$, valor percentual que indica similaridade de acordo com o índice de Jaccard (Magurran 1988), são áreas sem inundação situadas em Cabo Frio/RJ (Rezende 2004; Fernandes 2002, 2005), na área da Estação Rádio Marinha Campos Novos, e em Guarapari/ES no Parque Estadual Paulo Cesar Vinha (Assis et al. 2004). Este padrão de similaridade florística ligando blocos florísticos do Rio de Janeiro ao Espírito Santo, separados do bloco florístico sul Santa Catarina, Paraná e São Paulo tem sido encontrado inclusive em estudos sobre fitogeografia e florística das restingas fluminenses (Araujo 2000) e em análises floristicas da floresta atlântica (LeitãoFilho 1987; Siqueira 1994; Scudeller 2002). Na análise das listas de espécies arbóreas e arbustivas das áreas de floresta de restinga do Rio Grande do Sul a São Paulo, tendo como base os estudos listados na Tabela 4, verificase a ocorrência de famílias como Proteaceae, Cunoniaceae, Rosaceae, Symplocaceae, Styracaceae, Aquifoliaceae, Chloranthaceae e Podocarpaceae com poucas espécies, mas que são reconhecidamente grupos de áreas 
subtropicais e temperadas e cujas espécies por vezes participam com altos valores de importância na estrutura dessas florestas, como Euplassa cantareirae (César \& Monteiro 1995), Weinmannia paullinifolia (Sugiyama \& Mantovani 1994) e Ilex pseudobuxus (Dornelles \& Waechter 2004). Assim, essas misturas de floras nessas florestas do litoral sul e parte do sudeste espelham as condições climáticas de baixa temperatura e alta pluviosidade, que associados ao regime de inundação, funcionam como filtros seletivos para diversas espécies. São fatores que contribuem com a dissimilaridade entre a área estudada e as florestas situadas entre RS e SP. Também é expressivo mencionar a raridade e mesmo a ausência de espécies arbustivas e arbóreas de famílias como Melastomataceae e Arecaceae, respectivamente nas florestas sem inundação do ES (Assis et al. 2004) e RJ (presente estudo). Em áreas inundáveis do RS espécies como Syagrus romanzoffiana são de grande significância ecológica com elevada dominância (Dornelles \& Waechter 2004) ou ausentes nas amostragens (Waechter \& Jarenkow 1998), e por outro lado em área inundável e sem inundação em Bertioga/SP, Guedes et al. (2006) encontraram quatro espécies de Arecaceae sendo que Syagrus pseudoccocos, Euterpe edulis e Bactris vulgaris ficaram entre as 10 espécies mais importantes na estrutura comunitária da área inundável.

Com base nos dados de riqueza dos estudos apresentados naTabela 4 e na similaridade das florestas de restinga entre RS e ES (Tab. 6), as florestas com inundação apresentaram maior riqueza em São Paulo e as florestas sem inundação foram mais ricas no Rio de Janeiro. A separação da floresta atlântica em blocos (bloco sul-sudeste e bloco nordeste), parece também ser possivel nas restingas (pelo menos no bloco sul-sudeste), e explicariam também a

Tabela 6 - Coeficiente de Similaridade de Jaccard entre a floresta de restinga da Reserva Ecológica Estadual de Jacarepiá, RJ e áreas de floresta de restinga do litoral Sul e Sudeste

\begin{tabular}{lccl}
\hline Local & Latitude & $\begin{array}{c}\text { Coeficiente de } \\
\text { Jaccard (\%) }\end{array}$ & \multicolumn{1}{c}{ Referência } \\
\hline Setiba / ES & $20^{\circ} 35^{\prime}$ & 0,24 & Assis et al. 2004 \\
Grussaí / RJ & $21^{\circ} 44^{\prime}$ & 0,07 & Assumpção \& Nascimento 2000 \\
Carapebus / RJ & $22^{\circ} 15^{\prime}$ & 0,04 & Barros 2000 \\
Macaé / RJ & $22^{\circ} 16^{\prime}$ & 0,06 & Oliveira 2000 \\
Cabo Frio / RJ & $22^{\circ} 36^{\prime}$ & 0,48 & Fernandes 2005 \\
Cabo Frio / RJ & $22^{\circ} 41^{\prime}$ & 0,23 & Rezende 2004 \\
Armação dos Búzios / RJ & $22^{\circ} 43^{\prime}$ & 0,04 & Lobão \& Kurtz 2000 \\
Armação dos Búzios / RJ & $22^{\circ} 46^{\prime}$ & 0,17 & Fernandes 2002 \\
Arraial do Cabo / RJ & $22^{\circ} 56^{\prime}$ & 0,05 & Fonseca-Kruel et al. 2009 \\
Picinguaba / SP & $23^{\circ} 21^{\prime}$ & 0,04 & Cesar \& Monteiro 1995 \\
Bertioga / SP & $23^{\circ} 51^{\prime}$ & 0,04 & Guedes et al. 2006 \\
Bertioga / SP & $23^{\circ} 51^{\prime}$ & 0,06 & Guedes et al. 2006 \\
Ilha do Cardoso / SP & $25^{\circ} 04^{\prime}$ & 0,01 & Sugiyama \& Mantowani 1994 \\
Ilha do Mel / PR & $25^{\circ} 30^{\prime}$ & 0,05 & Silva et al. 1994 \\
Viamão / RS & $30^{\circ} 05^{\prime}$ & 0,02 & Waechter et al. 2000 \\
Itapuã / RS & $30^{\circ} 22^{\prime}$ & 0,03 & Scherer et al. 2005 \\
Tavares / RS & $31^{\circ} 29^{\prime}$ & 0,03 & Dornelles \& Waechter 2004 \\
Taim / RS & $32^{\circ} 30^{\prime}$ & 0,01 & Waecther \& Jarenkow 1998 \\
\hline
\end{tabular}


maior similaridade entre florestas costeiras dos trechos RS-SP e RJ-ES.

\section{A estrutura da floresta em relação ao DAP}

$\mathrm{Na}$ análise dos dados estruturais da floresta de Jacarepiá, comparados aos dados de outras florestas de restinga fluminenses (Tab. 5) que utilizaram o mesmo critério de inclusão (DAP $\geq 5$ ) e diferentes métodos de amostragem, observamos que Jacarepiá, além de mais rica em espécies e com elevado índice de diversidade, apresentou valor de dominância (área basal) menor que no estudo de Oliveira (2000) em área inundável, e valores inferiores aos demais estudos para a densidade. Esse dado deve ser interpretado com cautela, pois de acordo com as simulações realizadas por Gorenstein et al. (2007) o método de quadrantes influencia na precisão dos valores de densidade em função do padrão de distribuição das espécies, subestimando nas florestas com populações de padrão agrupado e superestimando nas florestas com populações de padrão regular. Além do mais, Dias \& Couto (2005) ao realizarem uma comparação entre três métodos de amostragem (quadrantes, parcelas e relascopia) utilizando também DAP $\geq 5 \mathrm{~cm}$ em dois blocos de repetição em diferentes áreas da floresta atlântica (ombrófila) em São Paulo, indicam que o método de quadrantes necessita de maior intensidade amostral pelo fato de amostrar menos indivíduos, apenas 12,4 e $13,4 \%$ da amostragem das parcelas, o que influencia diretamente na riqueza de espécies encontradas, isto é, amostrando entre 60 e $70 \%$ das espécies encontradas através das parcelas. Observadas as diferenças entre as áreas de floresta atlântica montana estudadas por Dias \& Couto (2005), aparentemente as áreas de restinga mais diversas comportam bem o uso de ponto quadrantes na avaliação da riqueza dessas florestas, haja visto os dados encontrados por Assis et al. (2004), que utilizando parcelas e o mesmo critério de inclusão encontrou 2.059 indivíduos e 92 espécies numa área de 1 ha enquanto nosso estudo com 800 árvores, ou 200 pontos, incluiu 108 espécies numa amostra equivalente a 0,5 ha. Essa equivalência foi informada através das análises realizadas pelo Programa FITOPAC (Shepherd 2006). As áreas de florestas de restinga estudadas no RS através de ponto quadrantes, indicadas em Dornelles \& Waechter (2004), com uso de $\mathrm{DAP} \geq 5$, embora pobres em espécies em relação ao litoral sudeste mostram riqueza variando de 18 espécies (120 indivíduos/30 pontos) a 47 espécies (400 indivíduos/100 pontos) enquanto um estudo utilizando parcelas incluiu 348 indivíduos e 48 espécies. Portanto, parece que do ponto de vista da reduzida riqueza dessas florestas em relação a floresta atlântica s.s., que o uso do método de ponto quadrantes em torno de 200 pontos seja um número mínimo recomendável para a avaliação da riqueza de espécies desses ambientes, observando as recomendações de Dias \& Couto (2005) e Gorenstein et al. (2007), bem como aquelas aplicadas por Durigan et al. (2002) para que os parâmetros de densidade e de dominância não apresentem viés.

Assim, a comparação do presente estudo com os demais estudos realizados nas florestas de restinga fluminenses é limitada em função da utilização do método do ponto quadrantes e de critérios mais excludentes (DAP $\geq 5 \mathrm{~cm}$ ) que a maioria dos demais estudos utilizando DAS $\geq 2,5$ ou DAP $\geq 2,5 \mathrm{~cm}$, este último critério além de mais includente também engloba as trepadeiras e hemiepífitas, já que esta metodologia segue Gentry (1982). A Tabela 4 mostra que em áreas sem alterações ou com leves alterações foi utilizado $\mathrm{DAP} \geq 2,5$ como critério de inclusão, e nos locais com perturbações severas foi utilizada $\mathrm{DAS} \geq 2,5$ cm (Sá 2002), sendo considerados bons critérios de inclusão para esses ambientes diversificados ao longo da costa. É possível a partir deste critério realizar filtragens por classes diamétricas que possam ser comparáveis a outros estudos que realizaram amostragens com critérios de inclusão mais utilizados como $\mathrm{DAP} \geq 5 \mathrm{e} \geq 10 \mathrm{~cm}$. Aparentemente a riqueza de espécies amostradas de acordo com Gentry (1982) nos estudos realizados em Cabo Frio (Rezende 2004; Fernandes 2005) está relacionada a extensão e largura locais da planície costeira 
próximas a foz dos rios Una e São João e não com a idade geomorfológica (holocênica) e que a riqueza em Jacarepiá esteja mais relacionada a idade do cordão litorâneo, mais interno (pleistocênico).

No contexto do Centro de Diversidade Vegetal de Cabo Frio, a área próxima a Cabo Frio e Armação dos Búzios é de alta riqueza de espécies, com diversidade estrutural representada por diversos tipos de formações florestais (sem inundação, com inundação, estacionais e ombrófilas) onde o manejo de recursos é possivelmente a causa da elevada área basal (Fonseca-Kruel et al. 2009) o que poderia induzir essas florestas a uma estrutura fortemente oligárquica. Nos estudos de Fernandes (2002), Rezende (2004) e Fernandes (2005) há uma indicação clara da riqueza e complexidade estrutural dessas florestas que se separam das demais pela maior densidade, riqueza de espécies, H' e área basal utilizando a mesma metodologia. A despeito das limitações comparativas do método de ponto quadrantes, utilizados neste estudo, com as áreas estudadas a partir de 0,1 ha e com critério mais inclusivo (Tab. 5), a área de Jacarepiá surpreende pela riqueza encontrada. A comparação direta com estudos realizados entre áreas de diferentes formações utilizando o método de ponto quadrantes e mesmo critério de inclusão em trechos de floresta atlântica fluminense (Peixoto et al. 2005; Rodrigues 1996; Kurtz \& Araujo 2000) indicam que Jacarepiá, embora em área de restinga, apresentou maior riqueza, dominância e densidade que o primeiro estudo e riqueza e dominância inferiores ao último estudo onde só foram amostrados 150 pontos, o que influenciou na comparação da densidade. Destaca-se no estudo de Peixoto et al. (2005) a presença de Pterocarpus rohrii entre as dez espécies mais importantes na estrutura daquela floresta, assim como em Jacarepiá.

Embora $41 \%$ das espécies tenham sido representadas por apenas um ou dois indivíduos, isto não significa que estas espécies sejam raras nas restingas. Por exemplo, na presente amostragem foi encontrado um indivíduo de
Byrsonima sericea, espécie comunissíma nas áreas de vegetação arbustiva aberta e na estrutura de áreas que sofreram distúrbios (Araujo \& Peixoto 1977; Araujo et al. 1997; Sá 2002).

\section{A estrutura da floresta em relação ao DAS}

A utilização das medidas tomadas ao nível do solo (DAS) têm sido utilizadas em áreas de floresta de restinga que sofreram perturbações (Araujo et al. 1997; Assumpção \& Nascimento 2000; Sá 2002), ajudando a compreender o processo de regeneração dessas áreas e fornecendo informações básicas sobre a estrutura da comunidade e espécies envolvidas neste processo. $\mathrm{Na}$ avaliação da estrutura da floresta de Jacarepiá, observamos que essa forma de mensurar, pouco comum em estudos de florestas sem perturbação, pode fornecer importantes dados sobre as espécies mais importantes na estrutura da floresta, com destaque para os troncos múltiplos que em diversos estudos são avaliados a partir da medida tomada a 1,30 $\mathrm{m}$ de altura do solo. Este procedimento pode mascarar os fustes reduzidos e rebrotas laterais.

$\mathrm{Na}$ avaliação dos parâmetros fitossociológicos utilizando o DAS, comparados ao DAP, observamos que entre as dez espécies mais importantes em VI, nove foram prevalentes, e as seis primeiras espécies se mantiveram na mesma ordem decrescente de VI enquanto três outras apenas mudaram de ordem. Entretanto, o parâmetro de dominância total aumentou de 23,3 $\mathrm{m}^{2} /$ ha para $39,2 \mathrm{~m}^{2} /$ ha, e que pode ser influenciado pelas seguintes razões: (a) forma dos troncos e raízes tabulares de algumas espécies como Eriotheca pentaphylla e Couepia schottii (b) o fato de que muito raramente as árvores exibem as mesmas medidas de diâmetro na base e a $1,30 \mathrm{~m}$ de altura e (c) pelos troncos múltiplos. Assim, do ponto de vista da análise estrutural e florística, esta forma de mensurar, pode ser complementar para a avaliação da estrutura, embora aumente o tempo de coleta de dados ao incluir uma segunda medida.

Em relação aos troncos múltiplos, com base nas medidas de DAS, a avaliação da 
riqueza de espécies com esta característica apresentou-se reduzida a 20 espécies, sendo 15 espécies com um único indivíduo e destaque para Pouteria grandiflora (5 indivíduos/14 troncos). $\mathrm{Na}$ avaliação da riqueza de espécies com troncos múltiplos considerados através do DAP, das 48 espécies assim consideradas destacam-se entre sete espécies com até 5 indivíduos com esses troncos: Algernonia obovata (9 indivíduos/28 troncos) e Pterocarpus rohrii (9 indivíduos/25 troncos). Pouteria grandiflora manteve o destaque em ambas as situações como espécie que ramifica-se desde a base. Sendo os troncos múltiplos, sempre citados como relacionados a perturbação e mesmo como característico das formações de restinga, é fundamental a inclusão das medidas de todas ramificações ao nível do solo, sem estabelecer critério de inclusão, mesmo quando as medidas forem tomadas a 1,30 m do solo (modo mais corriqueiro dos inventários florestais). Desta forma é possível avaliar posteriormente se as espécies apresentam troncos múltiplos desde a base (separados ou unidos) ou se são espécies arbustivas ou arbóreas de pequeno fuste ou ramificações laterais ou mesmo rebrotas a partir de um dado dano.

\section{Agradecimentos}

À Viviane S. Fonseca-Kruel, Miriam C.A. Pereira, Genise V. Somner, Luiz Sérgio Sarahyba, Luis Fernando T. Menezes, Jorge C. Gomes, Mauro J. Cavalcanti, Talita Fontoura Alves pelo valioso auxilio nos trabalhos de campo. Alexandre Christo e Bruno C. Kurtz na ajuda prestimosa com o FITOPAC. Ao JBRJ e a FEEMA pelo apoio institucional e logístico, Fundação O Boticário de Proteção a Natureza e CNPq pelo apoio financeiro.

\section{REFERÊNCIAS BIBLIOGRÁFICAS}

Almeida, A. L. \& Araujo, D. S. D. 1997. Comunidades vegetais do cordão arenoso externo da Reserva Ecológica de Jacarepiá, Saquarema, RJ. In: Absalão, R. S. \& Esteves, A. M. (eds.). Ecologia de praias arenosas do litoral brasileiro. Rio de
Janeiro. Oecologia Brasiliensis Series. Vol. 3. PPGE-UFRJ, Rio de Janeiro. Pp. 47-63.

Amorim, A. M. A.; Fiaschi, P.; Jardim, J. G.; Thomas, W. W.; Clifton, B. \& Carvalho, A. M. 2005. The vascular plants of a forest fragment in southern Bahia, Brazil. Sida, Contributions to Botany 21(3): 1726-1752.

Araujo, D. S. D. 1997. Cabo Frio Region. In: Davis, S. D; Heywood, V. H.; HerreraMacBryde, O.; Villa-Lobos, J. \& Hamilton, A. C. (eds.). Centres of Plant Diversity: a guide and strategy for their conservation. Vol. 3 The Americas. WWF/IUCN, Cambridge. Pp. 373-375.

2000. Análise florística e fitogeográfica das restingas do estado do Rio de Janeiro. Tese de Doutorado. Universidade Federal do Rio de Janeiro, Rio de Janeiro, 169p. \& Peixoto, A. L. 1977. Renovação de uma comunidade vegetal de restinga após uma queimada. Trabalhos do XXVI Congresso Nacional de Botânica. Academia Brasileira de Ciências. Pp. 1-17.

; Oliveira, R. R.; Lima, E. \& Ravelli Neto, A. 1997. Estrutura da vegetação e condições edáficas numa clareira de mata de restinga na Reserva Biológica Estadual da Praia do Sul (RJ). Revista Brasileira de Ecologia 1(2): 36-43.

; Sá, C. F. C.; Pereira, J. F.; Garcia, D. S.; Ferreira, M. V., Paixão, R. J.; Schneider, S. M. \& Fonseca-Kruel, V. S. 2009. Área de Proteção Ambiental de Massambaba, Rio de Janeiro: caracterização fitofisionômica e lista florística. Rodriguésia 60(1): 67-96.

Assis, A. M.; Pereira, O. J. \& Thomaz, L. D. 2004. Fitossociologia de uma floresta de restinga no Parque Estadual Paulo César Vinha, Setiba, município de Guarapari (ES). Revista Brasileira de Botânica 27(2): 349-361.

Assumpção, J. \& Nascimento, M. T. 2000. Estrutura e composição florística de quatro formações vegetais de restinga no complexo lagunar Grussaí/Iquipari, São João da Barra, RJ, Brasil. Acta Botancia Brasilica 14(3): 301-315. 
Barbiére, E. B. 1981. O fator climático nos sistemas territoriais de recreação. Revista Brasileira de Geografia 43(2): 145-265. 1997. Flutuações climáticas em Cabo Frio. Revista do Departamento de Geografia da USP 11: 95-112.

\& Coe-Neto, R. 1999. Spatial and temporal variation of the east fluminense coast and Atlantic Serra do Mar, State of Rio de Janeiro, Brazil. In: Knoppers, B.; Bidone, B. \& Abrão, J. J. (eds.). Environmental geochemistry of coastal lagoon systems, Rio de Janeiro, Brazil. Série Geoquímica Ambiental 6: 47-56.

Barros, A. A. M. 2009. Vegetação vascular litorânea da Lagoa de Jacarepiá, Saquarema, Rio de Janeiro, Brasil. Rodriguésia 60(1): 97-110.

Barros, M. J. 2000. Estrutura de uma mata inundável de restinga do Parque Nacional da Restinga de Jurubatiba, Município de Carapebus, Rio de Janeiro, RJ. Dissertação de Mestrado. Universidade Federal do Rio de Janeiro, Rio de Janeiro, 45p.

Bastos, M. N. C. 1996. Caracterização das formações vegetais da restinga da Princesa, Ilha do Algodoal, Pará. Tese de Doutorado. Universidade Federal do Pará, Belém, 261p.

Carvalhaes, M. A. \& Mantovani, W. 1998. Florística de mata sobre restinga na Juréia, Iguape-SP. IV Simpósio de Ecossistemas Brasileiros, Anais, Águas de Lindóia, SP. Vol 2. Pp. 37-47. (Publ. ACIESP 104.)

Carvalho Filho, A.; Lumbreras, J. F. \& Santos, R. D. 2000. Os solos do estado do Rio de Janeiro. In: Estudo geoambiental do estado do Rio de Janeiro. CPRM, Brasília. 1 CD-ROM.

Carvalho, F. A.; Braga, J. M. A.; Gomes, J. M. L.; Souza, J. S. \& Nascimento, M. T. 2006. Comunidade arbórea de uma floresta de baixada aluvial no município de Campos dos Goytacazes, RJ. Cerne 12(2): 157-166.

; Nascimento, M. T. \& Braga, J. M. A. 2007. Estrutura e composição florística do estrato arbóreo de um remanescente de mata atlântica submontana no município de Rio Bonito, RJ, Brasil (mata Rio Vermelho). Revista Árvore 31(4): 717-730.

Cesar, O. \& Monteiro, R. 1995. Florística e fitossociologia de uma floresta de restinga em Picinguaba (Parque Estadual da Serra do Mar), Município de Ubatuba, SP. Naturalia 20: 89-105.

Cirne, P. \& Scarano, F. R. 1996. Rebrotamento após o fogo de Andira legalis (Leguminosae) em restinga fluminense. In: Miranda, H. S.; Saito, C. H. \& Dias, B. F. S. (orgs.). Impactos de queimadas em áreas de cerrado e restinga. UNB, Brasília. Pp.128-137.

\& Scarano, F. R. 2001. Resprouting and growth dynamics after fire of the clonal shrub Andria legalis (Leguminosae) in a sandy coastal plain in southeastern Brazil. Journal of Ecology 89: 351-357.

Cronquist, A. 1988. The evolution and classification of flowering plants. $2^{\mathrm{a}}$ ed. The New York Botanical Garden, New York, 555p.

Dias, A. C. \& Couto, H. T. Z. 2005. Comparação de métodos de amostragem na floresta ombrófila densa -Parque Estadual Carlos Botelho/SP-Brasil. Revista do Instituto Florestal 17(1): 63-72.

Dillenburg, L. R.; Waechter, J. L. \& Porto, M. L. 1992. Species composition and structure of a sandy coastal plain forest in northern Rio Grande do Sul, Brazil. In: Seeliger, U. (ed.). Coastal plant communities of Latin America Academic Press, New York. Pp. 349-366.

Dornelles, L. P. P. \& Waechter, J. L. 2004. Fitossociologia do componente arbóreo na floresta turfosa do Parque Nacional da Lagoa do Peixe, Rio Grande do Sul, Brasil. Acta Botanica Brasilica 18(4): 815-824.

Dunphy, B. K.; Murphy, P. G. \& Lugo, A. E. 2000 . The tendency for trees to be multiplestemmed in tropical and subtropical dry forests: studies of Guanica forest, Puerto Rico. Tropical Ecology 41(2): 161-167.

Durigan, G.; Santos, J. D. \& Gandara, F. B. 2002. Fitossociologia de dois fragmentos 
de Floresta Estacional Semidecidual no Pontal do Paranapanema, SP. Revista do Instituto Florestal 14(1): 13-26.

Fernandes, D. S. 2002. Florística e fitossociologia de um trecho de floresta de restinga na praia de Manguinhos, Armação dos Búzios, RJ. Monografia de Bacharelado. Universidade Santa Úrsula, 48p. 2005. Estrutura de um trecho de floresta seca de restinga em Cabo Frio/ RJ. Dissertação de Mestrado. Instituto de Pesquisas Jardim Botânico do Rio de Janeiro, Rio de Janeiro, 40p.

Fonseca-Kruel, V. S.; Araujo, D. S. D; Sá, C. F. C. \& Peixoto, A. L. 2009. Quantitative ethnobotany of a restinga forest fragment in Rio de Janeiro, Brazil. Rodriguésia 60(1): 187-202.

Fontoura, T. A.; Rocca, M. A.; Schilling, A. C.\& Reinert, F. 2009. Epífitas da floresta seca da Reserva Ecológica Estadual de Jacarepiá, sudeste do Brasil: relações com a comunidade arbórea. Rodriguésia 60(1): 171-185.

Freitas, M. F. 1990/1992. Cactaceae da área de proteção, Rio de Janeiro, Brasil. Rodriguésia 42/44: 67-91.

Gentry, A. H. 1982. Patterns of neotropical plant species diversity. Evolutionary Biology 15: 1-84.

1995. Diversity and floristic composition of neotropical dry forests. In: Bullock, S. H. Mooney, H. A. \& Medina, E. (eds.). Seasonally dry tropical forests. Cambridge University Press, Cambridge. Pp 146-194.

Gorenstein, M. R.; Batista, J. L. F. \& Durigan, G. 2007. Influência do padrão espacial sobre a estimativa de densidade arbórea do método de quadrantes: um estudo por meio de simulação de Monte Carlo. Acta Botanica Brasilica. 21(4): 957-965.

Guedes, D.; Barbosa, L. M. \& Martins, S. E. 2006. Composição florística e estrutura fitossociológica de dois fragmentos de floresta de restinga no Município de Bertioga, SP, Brasil. Acta Botanica Brasilica 20(2): 299-311.
Kurtz, B. C. \& Araujo, D. S. D. 2000. Composição florística e estrutura do componente arbóreo de um trecho de Mata Atlânica na Estação Ecológica Estadual do Paraíso, Cachoeiras de Macacu, Rio de Janeiro, Brasil. Rodriguésia 51: 69-111.

Lacerda, L. D.; Araujo, D. S. D. \& Maciel, N. C. 1993. Dry coastal ecosystems of the tropical Brazilian coast. In: van der Maarel, E. (ed.). Dry coastal ecosystems of the world. Vol. 2B. Elsevier, Amsterdam. Pp. 477-493.

Leitão-Filho, H. F. 1987. Considerações sobre a florística de florestas tropicais e subtropicais do Brasil. Boletim IPEF 35: 41-45.

Lima, H. C. 2000. Leguminosas arbóreas da Mata atlântica: uma análise da riqueza, padrões de distribuição geográfica e similaridades florísticas em remanescentes florestais do estado do Rio de Janeiro. Tese de Doutorado. Universidade Federal do Rio de Janeiro, Rio de Janeiro, 151p.

Lobão, A. Q. \& Kurtz, B. C. 2000. Fitossociologia de um trecho de mata de restinga na Praia Gorda, Município de Armação de Búzios, Rio de Janeiro. V Simpósio de Ecossistemas Brasileiros, Anais, Vitória, ES. Vol. 3. Pp 66-73. (Publ. ACIESP no. 109).

Lopez, L. C. S., D’Elias, A. M. A. \& IglesiasRios, R. 1998. Fatores que controlam a riqueza e a composição da fauna aquática em tanques da bromélia Aechmea bromeliifolia (Rudge) Baker, na restinga de Jacarepiá-Saquarema/ RJ. In: Nessimian, J. L. \& Carvalho, A. L. (eds.). Ecologia de insetos aquáticos. Oecologia Brasiliensis Series, Vol. 5. PPGE-UFRJ, Rio de Janeiro. Pp. 91-100.

Magurran, A. E. 1988. Ecological diversity and its measurement. Princeton University Press, Princeton, 179p.

Martins, F. R. 1991. Estrutura de uma floresta mesófila. Ed. UNICAMP, Campinas, 246p.

Moreno, M. R.; Nascimento, M. T. \& Kurtz, B. C. 2003. Estrutura e composição florística do estrato arbóreo em duas zonas altitudinais na mata atlântica de encosta da região do Imbé, RJ. Acta Botanica Brasilica 17(3): 371-386. 
Mori, S. A.; Boom, B. M.; Carvalho, A. M. \& Santos, T. S. 1983. Ecological importance of Myrtaceae in eastern Brazilian wet forest. Biotropica 15(1): 68-70.

Muehe, D. \& Valentini, E. 1998. O litoral do estado do Rio de Janeiro. Uma caracterização físico-ambiental. FEMAR, Riode Janeiro, 99p.

Oliveira, R.C. 2000. Estrutura do componente arbóreo da mata periodicamente inundada do Parque Nacional da restinga de Jurubatiba, Rio de Janeiro, Brasil. Dissertação de Mestrado. Universidade Federal do Rio de Janeiro, Rio de Janeiro, 84p.

Oliveira-Filho, A. T. \& Fontes, M. A. L. 2000. Patterns of floristic differentiation among atlantic forests in southeastern Brazil and the influence of climate. Biotropica 32(4b): 793-810.

Peixoto, G. L.; Martins, S. V.; Silva, A. F. \& Silva, E. 2005. Estrutura do componente arbóreo de um trecho de floresta atlântica na Área de Proteção Ambiental da Serra da Capoeira Grande, Rio de Janeiro, RJ, Brasil. Acta Botanica Brasilica 19(3): 539547.

Pereira, O. J. \& Araujo, D. S. D. 2000. Análise florística das restingas dos estados do Espírito Santo e Rio de Janeiro. In: Esteves, F.A. \& Lacerda, L.D. (eds.). Ecologia de restingas e Lagoas Costeiras. NUPEM/UFRJ, Rio de Janeiro. Pp. 25-63.

Polhill, R. M.; Raven, P. H. \& Stirton, C. H. 1981. Evolution and systematics of the Leguminosae. In: Polhill, R. M. \& Raven, P. H. (eds.) Advances in legume systematics. Royal Botanic Gardens, Kew. Part 1. Pp. 1-26.

Rezende, G. S. Z. 2004. Estrutura de um trecho da floresta de restinga da Estação Rádio Marinha Campos Novos, Cabo Frio, RJ. Monografia de Bacharelado. Universidade Federal Rural do Rio de Janeiro. Seropédica, 39p.

Rocha, C. F. D.; Bergallo, H. G.; Van Sluys, M.; Alves, M. A. S. \& Jamel, C. E. 2007. The remnants of restinga habitats in the Brazilian Atlantic Forest of Rio de Janeiro state, Brazil: habitat loss and risk of disappearance. Brazilian Journal of Biology 67(2): 263-273.

Rodrigues, H. C. 1996. Composição florística e estrutura fitossociológica de um trecho de Mata Atlântica na Reserva Biológica do Tinguá, Nova Iguaçu, RJ. Dissertação de Mestrado. Universidade Federal do Rio de Janeiro, Rio de Janeiro, 77p.

Sá, C. F. C. 1992. A vegetação da restinga de Ipitangas, Reserva Ecológica Estadual de Jacarepiá, Saquarema (RJ): fisionomia e listagem de angiospermas. Arquivos do Jardim Botânico do Rio de Janeiro 31: 87-102. 1996. Regeneração em uma área de floresta de restinga na Reserva Ecológica Estadual de Jacarepiá, Saquarema/RJ: I Estrato herbáceo. Arquivos do Jardim Botânico do Rio de Janeiro 34(1): 177-192. 2002. Regeneração de um trecho de floresta de restinga na Reserva Ecológica Estadual de Jacarepiá, Saquarema, Estado do Rio de Janeiro: II - Estrato arbustivo. Rodriguésia 53(82): 5-23.

Sarahyba, L. S. 1993. Gramineae da Área de Proteção Ambiental de Massambaba. Dissertação de Mestrado. Universidade Federal do Rio de Janeiro, Rio de Janeiro, 145 p.

Scarano, F. R. 2002. Structure, function and floristic relationships of plant communities in stressful habitats marginal to the Brazilian Atlantic rainforest. Annals of Botany 90: 517-524.

Scherer, A.; Maraschin-Silva, A. \& Baptista, L. R. M. 2005. Florística e estrutura do componente arbóreo de matas de Restinga arenosa no Parque Estadual de Itapuã, RS, Brasil. Acta Botanica Brasilica 19(4): 717-726.

Scudeller, V. V.; Martins, F. R. \& Shepherd, G. J. 2001. Distribution and abundance of arboreal species in the atlantic ombrophilous dense forest in Southeastern Brazil. Plant Ecology 152: 185-199. 2002. Análise fitogeográfica da Mata Atlântica-Brasil. Tese de Doutorado. 
Universidade Estadual de Campinas, Campinas, 243p.

Shepherd, G. J. 2006. FITOPAC 1.6:Manual do Usuário. Universidade Estadual de Campinas, Campinas, 64p.

Silva, S. M.; Britez, R. M.; Souza, W. S. \& Joly, C. A. 1994. Fitossociologia do componente arbóreo da floresta de restinga da Ilha do Mel, Paranaguá, PR. In: III Simpósio de Ecossistemas da Costa Brasileira. Anais, Serra Negra, SP. Vol. 3. Pp. 33-48. (Publ. ACIESP no. 87-III).

Silva, G. C. \& Nascimento, M. T. N. 2001. Fitossociologia de um remanescente de mata sobre tabuleiros no norte do estado do Rio de Janeiro (Mata do Carvão). Revista Brasileira de Botânica 24(1): 51-62.

Siqueira, M. F. 1994. Análise florística e ordenação de espécies arbóreas da mata atlântica através de dados binários. Disssertação de Mestrado. Universidade Estadual de Campinas, Campinas, 143p.

Sugiyama, M. 1998. Estudo de florestas da restinga da Ilha do Cardoso, Cananéia, São Paulo. Boletim do Instituto de Botânica 11: 119-159.

Sztutman, M. \& Rodrigues, R. R. 2002. O mosaico vegetacional numa área de floresta contínua da planície litorânea, Parque Estadual da Campina do Encantado, Pariquera - Açu, SP. Revista Brasileira de Botânica 25(2): 61-176.

Trindade, A. 1991. Estudo florístico e fitossociológico do estrato arbustivo arbóreo de um trecho de floresta arenicola costeira do Parque Estadual das Dunas, Natal (RN). Dissertação de Mestrado. Universidade Federal Rural de Pernambuco, Recife, 168p.

Turcq, B.; Martin, L.; Flexor, J. M.; Suguio, K.; Pierre, C. \& Tasayaco-Ortega, L. 1999. Origin and evolution of the Quaternary coastal plain between Guaratiba and Cabo Frio, State of Rio de Janeiro, Brazil. In: Knoppers, B. A.; Bidone, E. D. \& Abrão, J. J. (eds.). Environmental geochemistry of coastal lagoon systems, Rio de Janeiro, Brazil. Série Geoquimica Ambiental 6: 25-46.

Waechter, J. L. \& Jarenkow, J. A. 1998. Composição e estrutura do componente arbóreo nas matas turfosas do Taim, Rio Grande do sul. Biotemas 11(1): 45-69.

; Müller, S. C.; Breier, T. B. \& Venturi, S. 2000. Estrutura do componente arbóreo em uma floresta subtropical de planície costeira interna.. In: V Simpósio Brasileiro de Ecossistemas, Vitória, ES. Anais. Vol. 3. Pp. 92-112. (Publ. ACIESP no. 109).

Whittaker, R. H. 1972. Evolution and measurement of species diversity. Taxon 21: 213-251.

Zickel, C. S.; Vicente, A.; Almeida Jr., E. B.; Cantarelli, J. R. R. \& Sacramento, A. C. 2004. Flora e vegetação das restingas no nordeste brasileiro. In: Eskinazi-Leça, E.; Neumann-Leitão, S. \& Costa, M. F. (eds.). Oceanografia: um cenário tropical. Ed. Bagaço, Recife. Pp. 689-701. 